\title{
Estudio sobre el catecismo pictográfico $\mathrm{F}$
}

\author{
LUIS RESINES LLORENTE \\ Profesor emérito del Estudio Teológico Agustiniano
}

Resumen: El esfuerzo por transmitir la fe en América llevó a los misioneros a sintonizar con las culturas de los indios y expresarla empleando su escritura ideográfica, a través de pictogramas en los que se fundan las dos culturas. Es uno de los raros ejemplares, que se nos ofrece descifrado, hasta donde permite el original, mutilado.

Palabras Clave: Pictográficos, testeriano, indios, evangelización.

ABSTRACT: The effort to communicate christian faith in America moved the missionaries to conect with indigeneous cultures and to express it using their ideographic writing, through pictograms in which both cultures converge. It is one of the very rare exemplars, now decoded. But it is defective.

KEYWORDs: Pictographics, testerian, indigenous, evangelization.

Los catecismos pictográficos, salvo raras y no muy seguras excepciones, son anónimos. Han surgido y se han seguido replicando a lo largo del tiempo sin que sea posible señalar un autor, en la casi totalidad de las ocasiones. Conocer al autor sería un procedimiento útil para dar nombre a cada uno de los catecismos que resultan conocidos; pero el anonimato no da lugar a ello. 
En otras ocasiones se los ha designado bien por la lengua en que aparece alguna anotación complementaria, o alguna frase espuria que alguien puso aprovechando una parte de papel que no estaba escrito, como ocurre con los designados como mazahua, tolucano,..; también se ha empleado la designación cuando habían un texto paralelo a los pictogramas, aunque no se correspondieran exactamente dibujos y texto escrito: es el caso del llamado náhuatl. Así algunos se han diferenciado de los otros, con la consiguiente claridad para el investigador.

El que estudio a lo largo de estas páginas carece también de identificación: no hay nombre alguno a quien asignárselo; tampoco hay escritura en alguna lengua, que lo distinga del resto. En cambio, sí tiene, como rasgo distintivo unos dibujos exquisitos, minuciosos, aunque de un tamaño muy reducido; pero están hechos con primor, y en algún caso con unos adornos cuidados que denotan una buena mano por parte del dibujante. En alguno de ellos aparecen exquisitas filigranas. $Y$ esto me ha animado a designarle, y por tanto a diferenciarle, con la letra $\mathrm{F}$, de filigrana. Frente a otros catecismos pictográficos que tienen dibujos toscos, imprecisos o confusos, el catecismo que ahora estudio es una preciosidad para la vista por lo cuidado de su presentación. Esto le distingue claramente de sus hermanos.

Cierto que todos ellos, con sus dibujos ingenuos, de pleno estilo naï, asombran por su belleza. Pero el presente ha llevado las figuras a un nivel de perfección notable. Sería, con una comparación, como si en una clase de dibujo contempláramos las láminas que han entregado los alumnos, entre las que unas están imperfectas, borrosas, con correcciones, mientras que otras aparecen limpias y exactas. Es lo que sucede con este catecismo.

\section{EL EJEMPLAR}

El ejemplar forma parte del fondo de la Tulane University, de Louisiana, incluido en la colección Mexican Pictorial Manuscripts, con 
la signatura: mpm00016. La descripción que proporciona la propia universidad, extractada, señala los siguientes puntos:

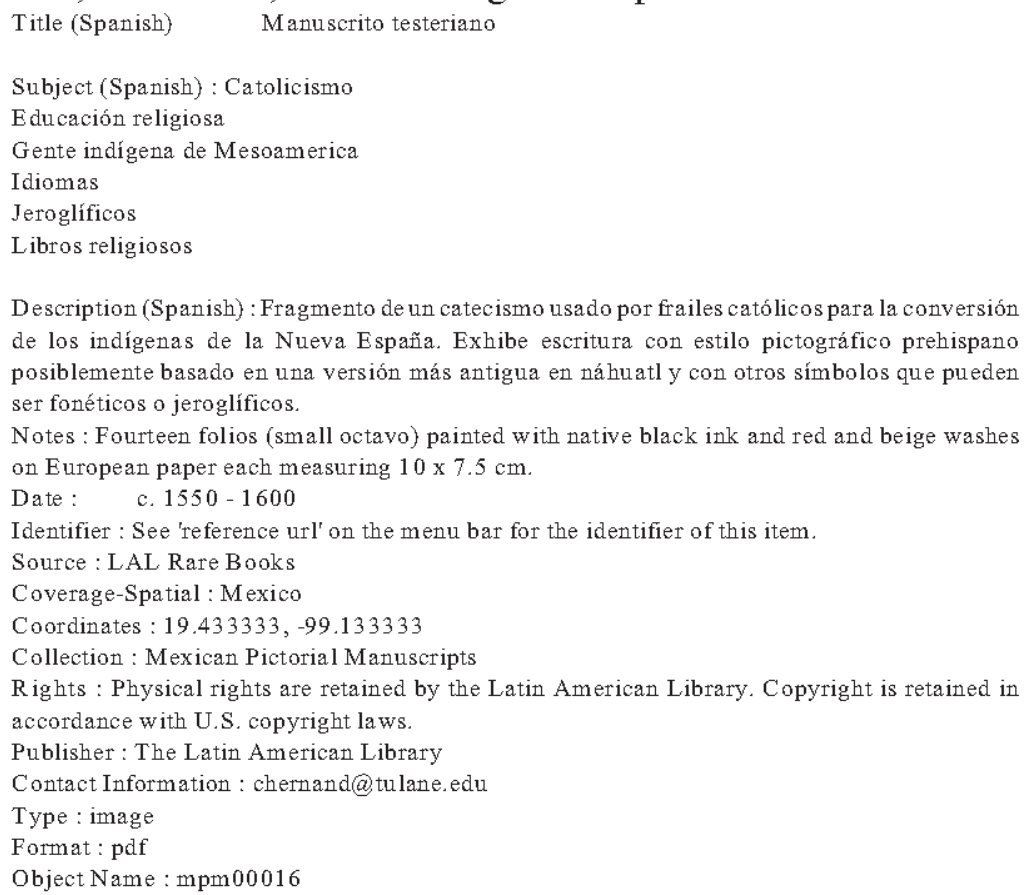

A falta de mejor información, detallada, como ya he indicado, se le ha asignado el título genérico de Manuscrito testeriano. Obedece a la tendencia, asentada entre los norteamericanos, de denominar "testeriano" a todo tipo de manuscrito, particularmente catecismos, con el criterio de que Jacobo de Testera fue el creador de este procedimiento, cuando en realidad no fue así, sino que, dado que no conocía la lengua náhuatl, para predicar se servía de cuadros que alguien había dibujado, que mostraba a su auditorio, mientras él predicaba en castellano, y un traductor se encargaba de vocear sus palabras vertidas en lengua náhuatl. Sigo creyendo que es mucho más exacto hablar de "catecismo pictográfico", dejando a un lado una atribución genérica, a la vez que inexacta.

Se trata en efecto, de un pequeño libro, de $10 \times 7,5 \mathrm{~cm}$., que conserva únicamente catorce páginas de las que pudo tener el texto completo en su origen. 


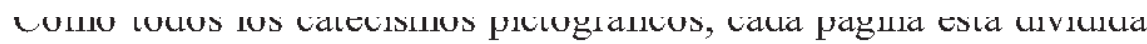
por unas líneas horizontales, lo que determina que haya unas bandas horizontales por las que discurren los pictogramas. En el caso presente, las cinco líneas generan seis bandas, que se mantienen inalterables en todas las páginas. Las líneas de separación estás hechas a mano, sin regla, pero son muy cuidadas. La altura de cada banda es aproximadamente 1,6 cm. En su interior, los pictogramas, en su mayor parte, tienen $1 \mathrm{~cm}$. de altura, por lo cual quedan suficientemente holgados. En cada página suele haber tres pictogramas por banda -es infrecuente que haya más - por lo cual también queda mucho espacio entre uno y otro.

Como es habitual en casi todos los catecismos pictográficos, abierto el librito, la lectura va desde el vuelto de una página hasta el recto de la siguiente, a lo ancho de todo el espacio que está a la vista. Esto hace que, al faltar páginas, la lectura e interpretación que trato de llevar a cabo encuentre un obstáculo insalvable en los lugares en que se producen esas mutilaciones. En algún caso es posible sospechar qué pudo haber en las páginas que faltan, cuando se trata de formularios conocidos. En otros casos hay que rendirse ante la dificultad.

La tabla que sigue muestra las páginas que existen, y a la vez, las que faltan, que aparecen sombreadas. Sin embargo en esas lagunas, no es fácil precisar cuántas faltan en cada ocasión. Al principio, antes de la p. 1 es probable que falten dos, ya que suele ser frecuente que los catecismos pictográficos comiencen por los formularios del padrenuestro y el avemaría, y por su extensión podrían ocupar dos páginas. En el resto de las ocasiones, no hay forma de saberlo.

No cabe acudir al hecho de que estos catecismos solían ejecutarse con unas hojas de papel más grandes, que, debidamente dobladas y cosidas en el centro daban como resultado un cuadernillo. Según este procedimiento, al romperse una hoja, lo esperado es que faltasen las páginas que ocupan lugares simétricos en el conjunto del cuadernillo. Pero, a la vista de las páginas conservadas, no se cumple en esta ocasión, y por consiguiente, puede suceder que en cada caso falte una página o más de una. Esta conclusión responde al contenido de los 
pictogramas, a través del estudio de la reproducción digitalizada (no el examen directo del manuscrito). Ese contenido, habitualmente con formularios propios de la fe cristiana, pero carentes de explicaciones, permite seguir hasta cierto punto lo que el texto enseñaba a sus lectores. De ahí que las deducciones de páginas no conservadas están basadas en la pérdida repentina de sentido en la lectura e interpretación de los pictogramas.

\begin{tabular}{|c|c|c|c|c|c|c|c|c|c|c|c|c|c|}
\hline \multicolumn{14}{|c|}{ Páginas existentes y páginas que faltan } \\
\hline 1 & 2 & 3 & 4 & 5 & 6 & 7 & 8 & 9 & 0 & 1 & $\frac{1}{2}$ & $\frac{1}{3}$ & $\begin{array}{l}1 \\
4\end{array}$ \\
\hline 8 & $\begin{array}{l}\mathrm{r}- \\
\mathrm{w}\end{array}$ & $\begin{array}{l}\mathrm{r}- \\
\mathrm{y}\end{array}$ & $\begin{array}{l}\mathbf{r}- \\
\mathrm{y}\end{array}$ & r- & v & $\mathrm{r}-$ & y & v & r- & y & $\mathrm{r}-$ & $\begin{array}{l}\mathrm{r}-\mathrm{y} \\
\mathrm{y}-2\end{array}$ & $r-$ \\
\hline
\end{tabular}

La consecuencia, penosa, es que no es posible afirmar cuántas páginas pudo tener la obra antes de que se produjeran las roturas que originaron la desaparición de algunas páginas. Y, como consecuencia, tampoco es posible hablar de un desciframiento completo, pues a la ausencia de algunas páginas hay que añadir la dificultad de descifrar las páginas conservadas, ya que, por la forma de lectura, a la p. 3vta. había de seguir una de las perdidas, cuyo recto haría sentido con la parte conservada; al interrumpirse el hilo de la exposición, no es posible seguir la lectura, que queda totalmente frenada.

A pesar de todas las dificultades, valía la pena intentar descifrar la obra, aunque fuera parcialmente, y creo sinceramente que el resultado no está totalmente descaminado, y proporciona una idea no sólo del conjunto de la obra, en forma global, sino de muchos detalles y páginas enteras cuyo contenido es posible ver con bastante claridad y precisión.

\section{AUTOR}

Ya he indicado el carácter absolutamente anónimo de este catecismo pictográfico. No hay en el mismo una sola pista gráfica ni manuscrita que permita aportar un nombre, o señalar una región o cultura 
mexicana en la que situar al autor de esta obra. Sí se percibe por el estudio detallado que se trata de una persona culta, que conoce bien el cristianismo y lo transmite con precisión.

No hay más remedio que recordar que, en realidad, los catecismos pictográficos fueron un esfuerzo intenso de colaboración entre los misioneros españoles y los tlacuiloque (dibujantes) mexicanos. En efecto, también en este catecismo se perciben con claridad algunos pictogramas que proceden nítidamente de la cultura europea que portaban los misioneros, mientras que otros son de procedencia mexicana y reflejan la cultura indígena. Esa simbiosis cultural es la que sirvió de vehículo de transmisión de la fe cristiana por medio de los pictogramas en que ambas culturas se fundieron, aunque no así las religiones, pues la cristiana aparece sin mezcla ni referencias al panteón mexicano.

En otros casos hay algún pictograma que representa la figura de un religioso; por su hábito se podría deducir a qué orden pudo pertenecer. No ocurre así en esta ocasión, porque al presentar los sacramentos, y en particular el del orden, aparece (F154) la representación de un sacerdote: su vestido es similar al del resto de las figuras representadas, y tan sólo le distingue un sombrero de tres picos (bonete) sobre su cabeza. Esto apunta más hacia un sacerdote secular, $o$, acaso, hacia un jesuita, pues vestían de la misma forma, y descarta la figura de algún miembro de orden religiosa. Como se ve, no es un argumento definitivo para aproximarse al autor o inspirador del catecismo. Pero no hay más pistas.

\section{FECHA}

La descripción reproducida antes, emanada de la propia universidad de Tulane, propone la fecha "c. 1550-1600", es decir, la segunda mitad del siglo XVI. La breve propuesta no indica alguna razón por la que inclinarse hacia ese momento; únicamente valdría la deducción lógica que es válida para otros catecismos, ya que todos aparecen sin fecha. Esto, por principio podría ser válido y podría darse por aceptable si se considerara aisladamente este catecismo. 
Pero al compararlo con otros, especialmente el que he denominado Catecismo pictográfico E, que existe en la John Carter Brown, de Providence, Rhode Island, se encuentran numerosas similitudes entre ambos. Concretamente hay dos pictogramas con un llamativo parecido: son los que representan la idea de Dios, y la de todo. El primero, con una curva que recuerda una " $\mathrm{S}$ " mayúscula invertida; y el segundo con una línea cruzada por varias paralelas. Esos pictogramas, que se encuentran en estos dos catecismos (salvadas las diferencias de dibujo), no se encuentran en los catecismos pictográficos que parecen más primitivos y más cercanos a la segunda mitad del siglo XVI. Hay algún pictograma más que relaciona los catecismos indicados. Esto induce a retrasar la fecha de composición por la razón complementaria de la posible fecha del pictográfico $E$.

En efecto, el catecismo pictográfico $E$ incluye entre los pictogramas escritura alfabética en castellano. Y el tipo de letra, la misma expresión en algunas palabras apuntan hacia una fecha que hay que situar en el siglo XVIII, a partir del año 1700 , pero sin más precisión.

Dado que estos dos catecismos de los que vengo hablando están tan próximos entre sí, para el Catecismo pictográfico $E$ es razonable pensar en el siglo XVIII, y, por afinidad, creo que habría que pensar en el siglo XVIII para el presente Catecismo pictográfico F. Los cien años de un siglo son margen suficiente para situar ambos, a falta de una precisión mayor. Por otro lado, no existe forma alguna de aventurar cuál de los dos catecismos pudo ser más antiguo, y cuál más reciente. Sí es posible deducir que el Catecismo pictográfico $E$ es copia de un ejemplar anterior (por algún error del tlacuilo). Pero eso no cambia las cosas, pues a lo largo de todo un siglo es posible pensar en la existencia de un ejemplar del que se hace una copia, y no es preciso que tenga que ser a partir de un ejemplar muy antiguo. El que el otro catecismo pictórico - el ahora estudiado- sea contemporáneo de la copia que hoy existe, no presupone necesariamente una mayor antigüedad.

Creo, por consiguiente, que la fecha más adecuada para este Catecismo pictográfico $F$ habría que retrasarla desde la segunda mitad 
del siglo XVI ("c.1550-1600") al siglo XVIII, por la similitud señalada. La semejanza en otros pictogramas, que no he indicado, se debe a que repiten patrones que habían sido plenamente aceptados por los destinatarios de los catecismos, y se encuentran en varios catecismos pictográficos. La semejanza que he destacado es la que no resulta tan común, $y$, por tanto, la que permite retrasar la posible fecha de este catecismo.

\section{NUMERACIÓN DE LOS PICTOGRAMAS}

El procedimiento que he seguido hasta ahora para estudiar estos catecismos pictográficos ha sido el de designar a cada catecismo con una clave (una letra) que lo diferenciara del resto de los pictográficos; a esa letra se añade el número que corresponde en orden correlativo a cada pictograma. Así, F002 es el segundo pictograma del catecismo $F$. De esta forma es posible diferenciar e identificar cada uno de los pictogramas, porque de otra forma sería complicado remitir, por ejemplo, al tercer pictograma que se encuentra en la segunda banda de la página cuarta de tal catecismo.

Numerarlos correlativamente parece tarea sencilla, pero no lo es tanto, pues en ocasiones hay pictogramas compuestos, constituidos por la suma de dos dibujos que aparecen por separado; o a veces hay algunos dibujos que carecen de significado y para los que cabe la duda de si numerarlos o no.

Pero en este catecismo en particular, dado que faltan páginas intermedias, (además de las iniciales y finales) hay una dificultad más. La vuelta de la p. 2 se inicia con los números F054, F055 y F056. Pero no es posible seguir numerando el recto de la p. 3 con F057..., ya que falta entre medias una página al menos.

La consecuencia ha sido tener que continuar la numeración por la vuelta de la página 2, hasta el final de esa página, (F054, F055, F056, F057...) y proseguir al comienzo del recto de la página 3 , con el número correspondiente: F071, F072... Era la única forma razonable de completar la numeración. 


\section{CONTENIDO}

El examen de los pictogramas permite una aproximación al contenido. Para ello he seguido dos criterios que se complementan entre sí.

El primero es que en determinados momentos aparece una serie de cuatro pictogramas seguidos, siempre en el mismo orden, que denotan sin duda alguna la conclusión de un formulario. Las equivalencias de estos cuatro pictogramas son: Asi / [se] haga / amén / Jesús. En realidad, constituyen una duplicación, pues es sabido que el amén hebreo, incorporado al castellano, significa así se haga; añadir la palabra Jesús ha sido una forma de devoción muy utilizada. Pero lo singular es que esto se encuentra expresado de la siguiente forma: el adverbio $A s i$, y el verbo se haga aparecen expresados con escritura pictográfica; por el contrario, para el sustantivo amén se echa mano de una mezcla de escritura manuscrita, la "A", con una forma similar a la pictográfica, y para el nombre propio Jesús, se acude de nuevo a la pictografía. Esto mismo había sucedido ya en el Catecismo tolucano (T), que mezcla dos pictogramas para: así / [se] haga, y luego, con escritura europea, "A" para: amén, y JHS para Jesús.

Este final de las oraciones aparece en todos los formularios, de manera que, cada vez que se encuentra está anunciando que termina una parte del catecismo y a continuación se inicia la siguiente. En este catecismo aparece seis veces, lo que muestra que hay siete partes. Además, reforzando ese final, y marcando la separación entre formularios, aparece en varios momentos una barra vertical, ancha y adornada, cuando ha terminado completamente un formulario. Figura en el credo, los sacramentos, la explicación sobre Cristo, y los artículos de la fe; no figura en los mandamientos de la Iglesia, ni en los mandamientos de Dios, y no es posible decir nada del último formulario, no identificado, ya que sólo aparece su comienzo.

El segundo criterio, resultado del desciframiento de los pictogramas, consiste en comprobar cuál es el formulario de que se está tratando en cada momento, para poder identificarlo, pues al reconocerlo, es posible seguir su desarrollo más fácilmente. 
La combinación de estos dos criterios permite señalar con una cierta duda, no resuelta, que el contenido del presente catecismo consta de las siguientes partes:

1. Credo (parcial); a continuación, quizá, salve (desde F057)

2. Mandamientos de la Iglesia

3. Sacramentos

4. Explicación no identificada, con repetición sobre Cristo (?)

5. Artículos de la fe (divinidad, y humanidad de Cristo)

6. Mandamientos de Dios

7. Otro formulario no identificado (parcial)

La parte cuarta no resulta demasiado clara, pues podría tratarse de dos apartados, uno sobre la trinidad y otro sobre Jesucristo en la misma exposición. Por otro lado, las dos series de artículos de la fe, relativos a la divinidad y a la humanidad de Cristo se pueden considerar como un único formulario. Son, pues, siete los contenidos incluidos en este catecismo.

\section{ADVERTENCIAS PREVIAS AL DESCIFRAMIENTO}

Lo primero que hay que señalar inevitablemente es que el desciframiento resulta parcial e incompleto, dado que la pérdida de algunas hojas hace imposible seguir la lectura con el recto o el vuelto de la página adjunta. Dicho esto, creo necesario indicar que en algunos casos es posible intuir lo que pudo haber en la hoja perdida, o en alguna de sus páginas, porque la parte conservada permite sospecharlo. Como la frecuencia ordinaria es de tres pictogramas por banda en cada página, en ocasiones es posible sospecharlo, sobre todo, cuando se trata de un formulario que resulta conocido. En otras ocasiones, no es viable, y las frases, o los simples pictogramas quedan inconexos, y no se puede llegar más lejos.

En las primeras hojas desaparecidas es muy posible que estuvieran presentes el padrenuestro y el avemaría, como está indicado. Desde luego es seguro que estaba parte del credo, porque ya en la primera página actual (f. 1r) se ve su desarrollo. 
No acierto a suponer qué pueda ser el formulario que he señalado en $4^{\circ}$ lugar, que parece ser una explicación que comienza con alguna referencia a la Trinidad, pero que después deriva en una presentación de la actuación de Jesús, paralela en gran manera al credo. El formulario final, en $7^{\circ}$ lugar, tampoco es posible desentrañarlo. Tiene una subdivisión interna, en partes numeradas; pero ni siquiera esa pista hace posible descubrir de qué se trata.

Llama poderosamente la atención el extraño orden en que aparecen los formularios en este catecismo, al menos los que resultan conocidos, ya que suele ser normal que primero se muestren los mandamientos de Dios, y después los de la Iglesia; y aquí sucede todo lo contrario, con la interpolación entre ambos de otros formularios más. No es fácil entender el motivo de semejante orden ni de la desconexión entre ellos.

Al fijarme en los dibujos propiamente dichos, ya he indicado su limpieza y nitidez, además de la espaciada disposición. En algunos casos hay verdaderas filigranas, como en el pictograma F011, que se refiere a María, exquisitamente adornado. También es posible señalar el pictograma F110, que no he sido capaz de desentrañar, pero que representa una figura humana con unos adornos esmerados sobre su cabeza (¿el papa?), aunque no es fácil tal significado, pues los religiosos que proporcionaban los criterios al dibujante hubieran sugerido algo parecido a una mitra, en lugar de esos adornos ostentosos.

Las figuras humanas están representadas de frente (cabeza redonda en que aparecen ojos, boca, y a veces nariz), o, con más frecuencia, de perfil. En este caso todos tienen un vestido que por la parte inferior cae en forma de triángulo y por debajo asoman los pies; además todos tienen un trazo a la espalda que semejara una capa, o una capucha. A veces el dibujo de alguien de perfil se completa con el rostro de frente (unos puntos para los ojos y la boca). Se distinguen perfectamente los hombres de las mujeres, por el peinado perfectamente diferenciado. Además, los que tienen algo divino, o, por extensión, celestial, tienen tres trazos sobre su cabeza y a ambos lados, para distinguirlos de los seres comunes. 
Como en otros catecismos pictográficos, aparece con frecuencia un "guía", un personaje sin ningún distintivo especial, que marca el sentido de la lectura, de izquierda a derecha, y hace avanzar la misma, pero que ordinariamente carece de significado propio.

Entre corchetes aparecerán aquellos elementos que hacen posible la articulación de una frase, pues los pictogramas sólo comunican ideas, no articuladas como el lenguaje oral o escrito. Señalaré con otro tipo de letra aquellas partes desaparecidas, pero de las que es posible suponer cuál fue su contenido (letra que permite la lectura, a la vez que resulta suficientemente diferenciada).

Con estas indicaciones, es el momento de iniciar la aventura del desciframiento.

\section{DESCIFRAMIENTO}

PARTE PRIMERA: CREDO (F004-F056)

El hecho de que falte una o varias hojas iniciales pero con absoluta certeza la que tendría que preceder al actual $\mathrm{f}$. 1r, permite en este caso sospechar gran parte de su sentido, porque es posible percibir que el formulario que desarrollan estas páginas es el credo. El aspecto de estas páginas sería así:

\begin{tabular}{|ccc|l|}
\hline \multicolumn{3}{|c|}{ Hoja no existente } & \multicolumn{1}{c|}{ f. 1r } \\
\hline$\ldots$ & $\ldots$ & $\ldots$ & $\begin{array}{l}\text { F001: rezo / F002: Señor / F003: } \\
\text { Jesucristo }\end{array}$ \\
\hline$\ldots$ & Creo & Dios & $\begin{array}{l}\text { F004: Padre / F005: este / F006: } \\
\text { hace }\end{array}$ \\
\hline cielo y & tierra Creo Jesús & $\begin{array}{l}\text { F007: todo humillado / F008: } \\
\text { concebido / F009: Madre }\end{array}$ \\
\hline María & Espíritu Santo nació & $\begin{array}{l}\text { F010: de / F011: Maria / F012: } \\
\text { virgen }\end{array}$ \\
\hline padeció & poder & Pilato & $\begin{array}{l}\text { F013: como hombre; F014: } \\
\text { crucificado / F015: muerto }\end{array}$ \\
\hline
\end{tabular}




\begin{tabular}{|c|c|c|c|}
\hline & & sepultado & $\begin{array}{l}\text { F016: bajo al infierno / F017: al } \\
\text { tercer dia / F018: resucitó }\end{array}$ \\
\hline
\end{tabular}

Tras el avance de lo que pudieron incluir las páginas iniciales perdidas, comienzo al análisis de los pictogramas, uno a uno.

F001

Una persona de perfil, que mira hacia la derecha en el sentido de la lectura del catecismo. Es fácil identificarlo con el "guía" que aparece en otros catecismos pictográficos, que hace avanzar la lectura, pero que ordinariamente carece de sentido propio. En esta ocasión tiene en su mano unas cuentas de rosario (un rosario), con una cruz, potenzada en lo alto. Su sentido podría ser: rezo.

F002

Se trata de una forma acorazonada, que se estrecha hacia abajo, y se curva primero hacia la izquierda y luego a la derecha. Siempre aparece unida a una cruz, en la parte superior; en la base de la cruz hay un pequeño rasgo hacia la izquierda. El pictograma por sí mismo no evoca nada, pero su sentido, por el contexto en que aparece es indudable: Señor.

F003

Aparece la figura de Jesús. Tiene en su cabeza los tres rasgos, como potencias por arriba y a ambos lados, dado su carácter divino. Está de pie, con los brazos abiertos, como si estuviera en la cruz, aunque ésta no aparezca en el dibujo. Su torso aparece como desdibujado por medio de unos pequeños arcos a cada lado, en lugar de una línea recta o curva que dibujara el pecho; pretende dibujar las costillas. Su sentido no ofrece duda: Jesucristo.

(Hay otro pictograma diverso, al término de los formularios, que se ha de interpretar como Jesús).

Siguen tres (?) pictogramas de la página desaparecida, en los que daría comienzo el credo.

Podrian significar: Ereotenturumicol Dios

F004

Una figura como la mayoría de las que aparecen en el catecismo tiene sobre su cabeza un sombrero de tres picos; aquí tiene un claro tono divino. El sentido, patente, es: Padre. (En F154 aparece el mismo pictograma, pero referido al padre, es decir, al sacerdote). 
ruUs

Una mano, la derecha, sostiene una cruz. Aparece con frecuencia, aunque no siempre es fácil dar con su sentido, pues no parece unívoco. Aquí, y otras veces, le cuadra el equivalente de: es, este es.

F006

Un rombo alargado, en posición vertical, con adornos en su interior, y con otros adornos curvados en sus puntas. Es un caso claro de cómo este pictograma fue empleado en otros catecismos, como el catecismo pictográfico $E$. Como era suficientemente entendido, no se hizo otra cosa más que seguir empleándolo. Su valor es: hacer, hacedor.

Los pictogramas de la página frontera, deberian expresar: cietoly tierra.fereotem fesús

F007

En un pequeño cuadrado asoma de frente el rostro de una persona. En la parte superior izquierda del cuadrado figuran unas líneas que se entrecruzan con otra vertical. Este segundo elemento del pictograma también consta con el mismo sentido en el catecismo E. Se interpreta como: todo. El conjunto se podría interpretar como: del todo humillado (rebajado).

F008

Precioso pictograma, que representa una mujer (rasgo denotado por sus cabellos), que mira de frente. El exquisito detalle es que en la parte inferior se adivina un rostro humano, que permite interpretar el pictograma como: concebido.

\section{F009}

Aunque sólo se vislumbra, por deterioro del original, no ofrece dudas, pues aparece en otras ocasiones, como en F066: una mujer en visión frontal (se perciben sus pechos), tocada también con un sombrero de tres picos (como F004). La equivalencia es: madre.

Los pictogramas que corresponderían a la página adjunta serian: por obra fdetEspiritusanto nació.

F010

La figura del guía, podría equivaler aqui a: de.

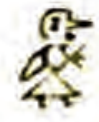

F011

Cuidado pictograma, con la figura de una mujer, de frente, con potencias en torno a la cabeza (carácter divino o sacral), además de dos bolas espinosas a la izquierda; 
tiene un vestido adornado. Se entiende como: María; las dos bolas espinosas, a la vista de F216, representarían la idea de: $\sin$ dolor, $\sin$ culpa.

F012

Un pequeño rectángulo en posición vertical alberga ocho pequeños puntos, de dos en dos; a la derecha hay una voluta rodeada de adornos curvos por el exterior. El sentido es claro, pues vuelve a aparecer más adelante: virgen.

Siguiendo el desarrollo del credo, los pictogramas que aparecerían en la página que falta deberían decir: padeció / por el poder/de filato

F013

Una " $\mathrm{A}$ " mayúscula tiene a su lado derecho una rama, que está unida a ella con una línea. Su sentido se comprueba en la otra ocasión (F386) en que sale este pictograma, en los artículos referentes a la humanidad de Jesús: como hombre.

F014

Sobre un pedestal de tres escalones aparece en el centro una cruz mayor que las habituales; a los pies de la cruz están dibujados dos clavos en posición oblicua. En el interior del pedestal, como adorno, una cruz en un pequeño montículo. Su valor es: crucificado.

F015

Hay un cadáver amortajado con vendas. A diferencia de otros pictográficos el rostro no está tapado, sino descubierto (ojos y boca). Lo que podría corresponder al brazo derecho está separado del cuerpo. El mismo pictograma aparece en otras muchas ocasiones, como F021, pero siempre en posición invertida respecto a éste. $\mathrm{La}$ cabeza hacia la izquierda y los pies hacia la derecha, con el brazo izquierdo separado . La interpretación es: muerto.

En la línea que habría de constar en la desaparecida página frontera, tendría que figurar algo así como: muerto /entre los muertos/seputtado.

\section{F016}

Una figura, que representa a Jesús aparece en el borde mismo de la mandíbula de un monstruo del que sólo se adivina la cabeza: unas descomunales mandíbulas llenas de terrorificos dientes, y en el extremo superior algo que podria ser un ojo; el resto, el cuerpo no aparece, sino solo una línea de puntos a la derecha de las fauces abiertas. Es similar a la representación de otros catecismos. Significa: bajó al infierno. 
F017

Tres circulos en bilera vertical, que representa el numeral; pero a la vez los círculos son rostros. No ofrece duda su desciframiento: al tercer dia.

F018

La figura de Jesús aparece vestida (no desnuda como en F003), con potencias en la cabeza, los brazos extendidos y un estandarte en su mano izquierda. (En esta ocasión el pictograma está incompleto, al estar situado en el extremo inferior y exterior del papel; aparece completo en F221). No cabe duda en la interpretación: resucitó.

F019

Aparece una persona de frente, con la cabeza aureolada de pequeños rayos.

Ha de entenderse como: glorioso.

F020

La letra " $A$ " tiene incorporado a la derecha un adorno en forma de curva con una serie de puntos en los extremos. La propia letra tiene también un punto en su interior. El sentido lo proporciona el desarrollo del credo: de entre.

F021

Un cadáver amortajado como el de F015 con la diferencia de que los pies están orientados hacia la derecha; y eleva el brazo izquierdo. No varía el sentido: muertos.

F022

Pictograma compuesto: una figura parecida a la de F019, tiene a sus espaldas lo que se podría considerar como un ala. Está en actitud de ascender por una escala representada por una linea quebrada; pero en lugar de tener escalones horizontales los trazos de la línea oscilan hacia arriba y abajo. Esta línea conecta con la segunda parte del pictograma: dos circunferencias concéntricas; en la de dentro hay una cruz, y en la corona intermedia una serie de puntos. (Aparecerá más adelante: F180, F190...) con el valor de: cielo. El pictograma completo se entiende como: subió al cielo.

F023

El mismo personaje (la cabeza con rayos) aparece de perfil, sentado en una silla de alto respaldo que se curva a la altura de la cabeza. El obvio lo que quiere decir: está sentado.

F024

Una mano como la de F005 está seguida del brazo, doblado, a cuyo extremo aparece una cruz. Se trata de la mano derecha, y ha de entenderse como: a la derecha. 
HUZS

Parecido a F023, quien está sentado en la silla es un personaje con un alto sombrero de tres picos, como el de F004. El hilo del credo aporta su equivalencia: del Padre.

F026

Pictograma abstracto, lineal, en que aparece una línea con doble curva, la de arriba cóncava hacia la derecha y la de abajo cóncava hacia la izquierda. Recuerda una "S" mayúscula cuya simetria lateral se hubiera invertido. Es un caso claro de semejanza con el catecismo pictográfico E, donde aparece el mismo signo, con la misma equivalencia: Dios,

F027

Aparece el mismo dibujo que en F006, acompañado, a la izquierda, de las líneas entrecruzadas que habían salido ya en F007: la suma de ambos sentidos da como resultado: todo hace.

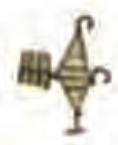

F028

Un rombo vertical alberga en su interior un pequeño círculo con un punto en el centro; a derecha e izquierda del rombo salen sendas volutas. El valor que hay que asignarle, acorde con el credo, es: desde alli.

\section{F029}

Parecido a F022, el mismo personaje (esta vez no tiene rayos alrededor de la cabeza) desciende por una escalera tan impracticable como la del pictograma aludido; pero es evidente lo que trata de comunicar: bajará.

F030

Igual a F010, con la equivalencia de: $a$, para.

F031

Pictograma complejo: en la parte superior hay una cabeza que se prolonga en el cuello; todo ello está sobre un pié (se perciben los dedos) que tiene en la parte superior una espada. Es similar en parte a los pictogramas del Catecismo tolucano (T205) y del de Sahagún (S164) que representan un pié sobre el que reposa una espada; y en otra parte similar al pictograma del Catecismo náhuatl (N184), en que la persona de Jesús tiende la espada a la altura del cuello de una persona a sus pies. Lo que se encuentra en este catecismo resulta una curiosa mezcla de ambos, si bien conserva plenamente su sentido: juzgar.

F032

Igual a F010, el guía evoca la preposición: $a$.

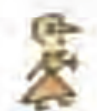


F033

Aparece aislado, sin ningún otro complemento el pictograma que había salido en F007 y en F027: una línea horizontal, entrecruzada por cuatro verticales. Significa: todo.

F034

Sobre una línea horizontal, que se curva en los extremos, están

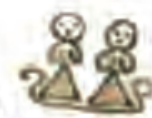
dibujadas dos personas. Hay, de nuevo, una correspondencia con el catecismo pictográfico $E$, donde aparece este mismo pictograma (precisamente fundido con el anterior, todo). E1 valor responde a: vivos.

F035

Aparece la figura del guía (F010), con la función de preposición: $a$.

F036

Igual que F021, con idéntica equivalencia: muertos.

F037 y F038

Pictogramas numerados por separado, pero que constituyen uno solo en realidad. F037 es igual a F010; F038 consta simplemente de una cruz potenzada. Lo que da a entender este pictograma compuesto es: creo.

F039

Es igual a F036, con el mismo valor: Dios.

F040

Hay una figura de carácter divino, por las potencias que rodean su cabeza. El cuerpo, en cambio, no tiene forma humana, sino que está formado por unas amplias curvas a los lados, que terminan estrechándose por la parte inferior; en el interior está marcada una cruz. Es visible un brazo, tendido hacia una forma constituida por un triángulo agudo con un vértice en la parte superior; está atravesado de arriba a abajo por una línea recta que se curva en lo más alto hacia la izquierda. Su sentido ha de ser forzosamente: Espiritu Santo.

F041

Repite la figura del guia (F010). Aquí puede tener el sentido de pronombre: que.

E042

Es igual al pictograma F006. Significa: hace.

F043

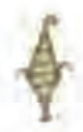

Un cuadrado pequeño alberga una cruz. Le rodea otro más grande 
adornado por dentro y fuera de una linea de puntos. Sobre ambos campea una que arranca en un costado del pequeño. El pictograma equivale a: Iglesia.

F044

En la parte inferior hay dos circulos irregulares que se entrecr ambos tienen una línea punteada inferior (Podría representa campana vista desde abajo). En la parte superior, una 1 horizontal, con rayos en torno a la cabeza (signo divino) y un $\mathrm{c}$ (o prolongación) en forma triangular, alargada, rodeada también de peq lineas. Podría tratarse de la idea de: católica, asociada a la Iglesia.

F045

Hay una larga cruz, con una especie de soporte en la parte inferior, y un banderola desde su astil, hacia la derecha. Vuelve a aparecer poco después Podría tratarse del adjetivo: formada, constituida.

\section{F046}

En un círculo amplio están insertas cuatro pequeñas caras. Parece claro que trata de expresar la idea de: unión.

F047
Lo mismo que F033, equivale a: IIII todos.

F048

Hay una figura que en la parte superior está formada por varios pequeños con la parte curva hacia el interior y los extremos hat exterior; casi forman un círculo, pero la figura se alarga y estrecha abajo, hasta unirse las líneas que la prolongan. Es posible que el se que mejor le cuadre (pues aparece en más ocasiones) sea el de: sante

F049

Se ve a una figura como la del guía, pero tocada con un sombrero c ancha, a la española. Parece que el equivalente seria: Padres. Pero corresponde con la imagen de Dios Padre (F025), ni a la idea de como sinónimo de sacerdote. Son más bien los Padres de la Iglesia, lc la constituyeron en el pasado. Más adelante adquirirá otro sentido par (hombre), pero no igual.

F050 y F051

De nuevo figuran juntos los dos pictogramas, que expresan: creo.

F052

Repite idéntico F045, con el mismo valor: formada, constituida.

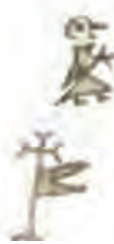


F053

Aunque deteriorada al estar en la parte inferior de la página, aparece la misma figura que en F046: unión.

F054

Igual que el pictograma $\mathrm{F} 033$, conserva el mismo valor: todos.

HII

F055

Como F048, conserva su sentido: santos.

F056

Un dibujo prácticamente igual que la figura que acompañaba en el pictograma F040 al Espíritu Santo: Una especie de pequeño triángulo, con dos trazos curvos en la parte superior, y una recta que pasa a todo lo largo y sobresale por debajo. Puede ser la representación esquemática de una campana. Su valor hay que suponerlo a partir del texto del credo, y podría ser: la vida o también la vida eterna.

(Ver F418 con un dibujo similar).

A partir de aquí, por la pérdida de una (o más de una) hoja, se interrumpe el sentido. Al haber culminado prácticamente el recitado del credo, no resulta aventurado sospechar que a continuación vendría el doble final que se encuentra en otros formularios de este catecismo, y que sería: asi se haga; amén Jesús. Este final podria ocupar la banda primera de la hoja perdida.

El desciframiento del credo podría quedar de la siguiente forma, teniendo en cuenta que la mayoría de los pictogramas que corresponden a este formulario se conservan o resulta bastante probable imaginarlos:

Ereo en Dios Padre este es [el que] hace et cieto y ta tierra. Creo en Jestis humillado concebido [por su] madre por obra del Espiritu Santo, ella María sin

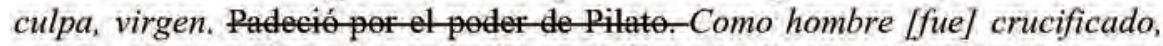
muerto y(...) seputtado, bajó al infierno; [al] tercer día resucitó glorioso de entre [los] muertos. Subió al cielo; está sentado a la derecha [del] Padre Dios todo hacedor. Desde alli bajará para juzgar a todos [los] vivos y muertos. Creo en Dios Espiritu Santo, que hace [la] Iglesia católica, formada [por la] unión [de] todos los santos padres. Creo [que] formada [la] unión [de] todos [los] santos [en la] vida eterna. 
Los pictogramas que se conservan en el f. $2 v$, tendrían que completarse con los que aparecerian en el resto de la hoja, y ni siquiera es posible intentar su desciframiento, pues resulta entrecortado y notablemente fragmentario.

El resto de la página perdida, junto con la hoja 2 vuelta, conservada, tiene este aspecto:

\begin{tabular}{|l|ccc|}
\hline \multicolumn{1}{|c|}{ f. 2v } & \multicolumn{3}{|c|}{ página que falta } \\
\hline F057: el que / F058: hace/ F059: ? & $\ldots$ & $\ldots$ & $\ldots$ \\
\hline F060: todo / F061: ... /F062: .. & $\ldots$ & $\ldots$ & $\ldots$ \\
\hline F073: ... / F064: ... / F065: asi como & $\ldots$ & $\ldots$ & $\ldots$ \\
\hline F066: madre/ F067: mujer santa & $\ldots$ & $\ldots$ & $\ldots$ \\
\hline $\begin{array}{l}\text { F068: que / F069: corazón/ F070: } \\
\text { que }\end{array}$ & $\ldots$ & $\ldots$ & $\ldots$ \\
\hline
\end{tabular}

Es posible percibir que resulta inviable una aproximación a lo que esta página podría contener. Tan sólo una mera hipótesis: que si en múltiples ocasiones al credo sigue la salve, cabría pensar en esta oración como ocurre en otros catecismos pictográficos o no pictográficos; por otro lado, los pictogramas F066 y F067 se refieren a los sentidos de Madre y mujer santa, que podrían encajar en la salve, aunque no se puede precisar nada.

F057

Imagen del guía. Podría significar: quien

F058

Igual al pictograma F006, equivale a: hacer.

F059

Raro pictograma, que no aparece más que una vez. En la parte inferior hay un círculo que aloja en su interior siete puntos; en la parte superior, juntas, por el exterior aparecen tres cruces. Quizá podría significar: salvación (?).

F060

Igual a F047, su valor es el de: todo.

F061 y F062

Aparece seguida en dos ocasiones la imagen del guía. No es fácil suponer significado alguno, al faltar la continuación de la banda, y, por tanto, el sentido. 
1063 y 1064

Lo mismo que ocurría antes, también está repetida la imagen del guía; y tampoco es posible imaginar qué tratan de decir.

F065

Una figura curiosa. De no ser porque aparece en otros catecismos pictográficos, no sería fácil descubrir de qué se trata: es el dibujo de un conejo o liebre, en el que destacan de forma sorprendente las dos grandes orejas, sobre una cabeza redonda, que tiene una especie de pequeña trompa (redondeada) en la parte derecha. Se perciben bien las cuatro patas del animal, así como un rabo ensortijado. En otros pictográficos (T021, T091, S051, E007) aparece un dibujo parecido, con un significado preciso: como, asi como.

Precisamente este adverbio comparativo reclama un segundo término con que comparar, y es una razón poderosa para comprobar que precisamente aquí falta una hoja, pues de no ser asi, habría que comparar con lo que sigue en el resto de la banda, y daría algo tan absurdo como: ... el, el asi como dos...

\section{F066}

Igual que F009, con la diferencia de que aquí se percibe bien el dibujo, cosa que no ocurría allí. Significa: madre.

\section{F067}

Hay una mujer, reflejada por sus cabellos, que tiene en su mano el mismo dibujo del pictograma F048 y F055, que representaba la idea de: santos. El pictograma actual, sería, pues: mujer santa.

En F241 el mismo signo aparece dibujado junto a una mano.

F068

De nuevo aparece la figura del guía, sin ningún atributo especial, lo que hace dificil precisar su sentido.

F069

Muy apaisado, lo que muestra el dibujo es un corazón, que tiene en la parte superior una extensión a modo de cubierta, y en su interior aloja dos pequeñas volutas. Parece que ése es su valor: corazón, o también voluntariamente.

F070

De nuevo aparece el guía, sin nada especial, difícil por tanto de descifrar. En este f. $2 v$, este mismo pictograma consta en siete ocasiones; si a eso se añade la ausencia de la hoja frontera, se percibe lo difícil que es aventurar un sentido posible.

Esta ausencia de pictogramas se prologaría también en la primera banda de la 
vuelta de la hoja desaparecida, pero concluye en la parte conservada del f, $3 r$. En esa ocasión he aglutinado en un solo pictograma todo el final, pues al dibujante le sucedió lo mismo: que por falta de espacio hubo de acumular pictogramas, y el que representaría amén no llegó a dibujarlo:

\begin{tabular}{|c|c|c|c|}
\hline$\ldots$ & $\cdots$ & $\cdots$ & $\begin{array}{l}\text { F071: como / F072: vivos / F073; } \\
\text { asi: F074: [se] haga; [amén] Jesús }\end{array}$ \\
\hline
\end{tabular}

F071

La misma imagen del pictograma F065; su valor es: como.

F072

El mismo pictograma que en F034; se interpreta como: vivos.

F073

Repetición de F065. Equivale a: asi.

F074

He reunido dos pictogramas, muy apretados, en el extremo de la banda. Uno es igual a F006, y significa: hacer; el otro es un círculo con una pequeña cara rodeada de rayos. Significa: Jesús.

Hay que notar que no es igual al que figura más adelante (F119); pero sí al que seguirá después (F166), También destaco que en esta fórmula conclusiva, falta el amén, (queda como asi [se] haga, Jesús), que aparece en otras ocasiones, y resulta en cierto modo incompleta.

Hay, además, una línea de separación, a la conclusión del formulario.

\section{PARTE SEGUNDA: MANDAMIENTOS DE LA IGLESLA (F075-F119)}

Sigue el catecismo con otro formulario, los mandamientos de la Iglesia. Lo llamativo es que aparecen en un lugar nada habitual, porque lo ordinario es que primero figuren los mandamientos de Dios, y a continuación los de la Iglesia. Hay en ello una razón teológica de peso, dada la principal importancia que tiene el decálogo en sí mismo, como palabras reveladas, que conectan con la moral universal. Por el contrario, los mandatos de la Iglesia con prescripciones humanas, de tipo auxiliar, carentes de carácter revelado, y sometidas, como todas las decisiones eclesiásticas, a posibles revisiones y cambios. Precisamente por eso extraña el doble uso de situar desconectados ambos formularios, y anteponer los de la Iglesia a los de Dios.

Falta la hoja que precede al f. $3 r$, por lo que la reconstrucción del inicio de este formulario es hipotética en parte. El cuadro auxiliar, como en otras ocasiones, 
puede dar una idea de lo que se conserva y de lo perdido, que es necesario intur:

\begin{tabular}{|c|c|c|}
\hline & Hoja que falta & f. $3 r$ \\
\hline $\begin{array}{l}\text { Estos } \\
\text { tajmadre }\end{array}$ & mandanientos [de & $\begin{array}{l}\text { F075: Iglesia / F076: son / F077: } \\
\text { cinco }\end{array}$ \\
\hline$\cdots$ & $\cdots$ & $\begin{array}{l}\text { F078: primero / F079: misa / F080: } \\
\text { acudir }\end{array}$ \\
\hline domingos & fiestas & $\begin{array}{l}\text { F081: segundo / F082: confesar / } \\
\text { F083: pecados }\end{array}$ \\
\hline $\begin{array}{l}\text { todos } \\
\text { Pasena }\end{array}$ & losaños & $\begin{array}{l}\text { F084: una vez / F085; dolor / F086: } \\
\text { nombre / F087: confesión }\end{array}$ \\
\hline tercero & cuerpo & $\begin{array}{l}\text { F088: Señor / F089: Jesucristo I } \\
\text { F090: nombre /. F091: comunión(?) }\end{array}$ \\
\hline
\end{tabular}

F075

Es similar a F043, con la diferencia de que el edificio tiene en lo alto dos cruces en lugar de una, más una banderola que sale de la segunda. En el interior del dibujo se adivina una especie de altar (pedestal?) con una cruz. No parece que cambie su sentido: Iglesia.

A este pictogramas precederían los que equivaldrian a: Estos mandamientos $[$ de ta] madre.

F076

Es repetición del pictograma F005, conservando su sentido: estos.

F077

Es la primera vez que sale en este catecismo un pictograma con números. Son los que aparecen en los formularios que están subdivididos con enumeraciones de varios apartados, para ser aprendidos y recitados. Constan cinco círculos en línea vertical: cinco.

F078

Un círculo sólo constituye la expresión del ordinal: el primero.

No intuyo qué podría aparecer en los pictogramas anteriores, que faltan.

F079

Bonito dibujo orientado hacia la izquierda. En esta parte hay primero dibujada una cruz sobre un extraño soporte, en línea quebrada; sigue 
después una mesa, la mesa de altar sobre la que aparece algo con un trazo curvo (¿querría representar el cáliz?), y un libro, el misal; más a la derecha, el sacerdote está arrodillado, con casulla, y sostiene en las manos el pan para la eucaristía. El conjunto expresa con claridad su valor: misa.

F080

Aparece el guía, que en esta ocasión tiene un pequeño rasgo distintivo, pues en la parte izquierda de la cabeza — mal colocado- está dibujado el oído. Ése es precisamente su sentido: oír.

Seguiria en los pictogramas que faltan: tomingos y fiestas.

F081

Hay dos círculos pequeños en hilera, como los números. Es: el segundo.

F082

La primera parte del pictograma presenta un dibujo igual que F025. La segunda parte presenta, a la derecha, una persona arrodillada ante él. Es claro que el pictograma no tiene el mismo valor que $\mathrm{F} 025$, que representaba a Dios Padre. Igual que ocurre con las palabras con varios sentidos, aquí representa al padre, al sacerdote, que lleva a cabo el ministerio de la confesión hacia el penitente arrodillado, Su sentido es: confesar.

F083

Una ancha figura, alargada, se desliza hacia abajo haciendo una doble curva, primero hacia la derecha y luego hacia la izquierda; a medida que baja, se va estrechando. En la parte alta hay dibujados unos puntos. Volverá a aparecer en F362 y F363, donde se aprecia con más claridad que es el dibujo de una serpiente. Es el animal que por antonomasia representa el pecado, y eso significa: pecado.

Aqui seguirian los pictogramas que expresarían el equivalente a: eada añofport Paserra.

F084

Hay un simple círculo pequeño, como F078, aunque parece que aquí encaja mejor el sentido: una vez.

F085

El guía tiene dibujada ante su boca una pequeña cruz. El sentido podría equivaler a: con dolor, o con verdad.

F086

Un pequeño cuadrado está cruzado por líneas en su interior, como cuadrícula; en la parte izquierda, hay dos rasgos curvos uno arriba y otro abajo. Su equivalencia (pues saldrá en más ocasiones) es: nombre. 
FU87

Un doble cuadrado, a modo de atril o facistol tiene una cruz en el interior; hay otra cruz en la parte superior; a los lados, unos adornos curvados lo realzan; y por abajo aparece un soporte que sostiene todo. No parece que haya dudas en interpretarlo como: confesión.

Seguirían los pictogramas que expresarían: fefterecrorecibir [et]cterpo.

F088

Igual que F002, conserva su valor expresivo: Señor.

F089

Igual que F003, con la diferencia de que aquí se ve mejor el cuerpo, aunque peor los pies de la figura dibujada: Jesucristo.

F090

Reproduce el pictograma F086, con el mismo valor: nombre.

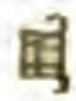

F091

Pictograma que se conserva mutilado, por estar en la parte inferior externa de la hoja: Se adivina algo que evoca la imagen de F043: un cuadrado o rectángulo rodeado de puntos externos y con una cruz en la parte superior. El contexto de los mandamientos de la Iglesia apunta cuál ha de ser su sentido: comunión.

F092

Repite el pictograma F005, con el sentido singular de: es.

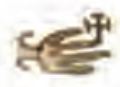

F093

Aparece de nuevo F086, con el significado de: nombre.

F094

El mismo pictograma de F075, con la diferencia de que en el interior un rectángula aloja dos cruces; tiene el mismo valor: Iglesia.

Ahora bien, si los pictogramas F090 y F091 equivalian a: [su] nombre comunión, por el sentido marcado por el formulario, ahora, a continuación se repiten los mismos dibujos en F092, F093 y F094 con la misma secuencia: es [su] nombre comunión, también por el sentido del formulario. Es posible que estemos ante un caso de error del dibujante, tlacuilo, quien, al copiar de otro manuscrito anterior, y pasar página, inadvertidamente repitiera los pictogramas últimos. No se entiende de otro modo.

F095

Cuatro círculos en linea vertical; denota el ordinal: el cuarto. 
F096

Pictograma que representa al guía, sin más. En este caso ha de entenderse que trata de representar la idea de: ayunar, tanto por el desarrollo de los mandamientos eclesiásticos, como por similitud con el catecismo pictográfico $E$, que en este punto representa el mismo dibujo, pero con la peculiaridad de que la parte inferior del personaje está sombreada, para señalar algo distinto de lo normal. Es, pues: ayunar.

F097

Hay un círculo, algo deformado, con cinco puntos en su interior, y una cruz en la parte superior. Representa la idea de: mandar, por el enunciado del mandamiento.

Volviendo la vista atrás, F059 se parece mucho a este pictograma, aunque tenga tres cruces en lugar de una sola, pero parece que no corresponde allí el sentido de mandar que aquí sí cuadra.

F098

Igual que F066, ha de entenderse como: madre.

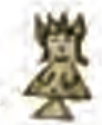

F099

Igual que F075, representa la: Iglesia.

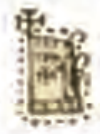

F100

Cinco círculos pequeños dispuestos en orden vertical: el quinto.

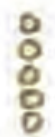

F101

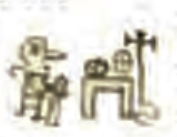

Una persona está sentada frente a una mesa (igual que la de F097), sobre la que aparecen dos círculos divididos en cuatro partes; a la derecha de la mesa hay una cruz, en un extraño soporte que termina en doble curva (parecido también a F097). En el presente pictograma, esos círculos divididos han de entenderse como monedas, dinero, mientras que en F097, una representación igual, en el contexto de la misa, había de entenderse como pan. La diferencia la marca el contexto de los mandamientos de la Iglesia, y equivale a: pagar.

F102

Aparece el número diez en dos columnas de círculos, con siete en la primera y tres en la segunda. El sentido resulta claro: diez.

F103

El mismo pictograma que F086: nombre,

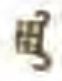

F104

Extraño pictograma: a la izquierda un rectángulo con nueve puntos en 
su interior, a su derecha, dos triángulos con un vértice hacia el rectángulo, uno con tres puntos, y el otro vacio; más a la derecha, dos volutas rodeadas por el exterior con curvas de puntos. No aparece más que una vez. El sentido está marcado por el formulario del mandamiento: diezmos.

F105

El mismo pictograma que F086, significa: son.

\section{F106}

Una persona de frente tiene los brazos abiertos y en cada uno de ellos está dibujada una llave. Por similitud con otros catecismos pictográficos, en el mismo contexto de los mandamientos, el sentido que le corresponde es: guardar.

\section{F107}

Ante la persona del guía, aparece un pequeño círculo con un punto en su interior, que podría representar un ojo. Podría cuadrar el valor de: ver.

F108

Igual que F048, remite a la idea de: santos.

F109

Similar a F034, aunque carece de la línea inferior que sustentaba y envolvía a las dos personas representadas. Podría suponerse el mismo sentido, aunque el conjunto de esta frase resulta enigmática, especialmente por algunos de los pictogramas que siguen. Habría que pensar en: vivos.

\section{F110}

Hay un rostro dibujado de frente, con ojos, nariz y boca; además tiene cabellos, barba y bigote. Por encima de su cabeza tiene dos largos cuernos ramificados en ostentosas volutas, al modo de la cuerna de un ciervo. ¿Podría tratarse de una representación ritual, como la conocida "Danza del venado" mexicana?. No he dado con algún sentido que pudiera corresponder.

\section{F111}

Es el mismo pictograma de F006, con el sentido de: hacer.

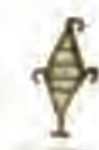

F112

Repite F046, que corresponde a: unión. 
F113

Igual que F086, su valor es: nombre.

\section{F114}

Pictograma que tiene otra aparición en el catecismo: un pequeño círculo dibuja un rostro humano (ojos, boca), en las cuatro direcciones se abren cuatro triángulos agudos, como si fueran pétalos de una flor; $y$ en las diagonales de esos triángulos aparecen cuatro cruces. El sentido que pudiera corresponder a este pictograma es: sagrado.

\section{F115}

Está el guía y a la altura de su boca, un triángulo, como una bocina, de la que salieran sonidos emitidos por el personaje; están representados por pequeñas líneas divergentes. El pictograma podría ser: anuncio.

\section{F116}

Igual que F065, equivale a: asi

\section{F117}

Como F006, representa la idea de: hacer.

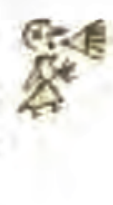

\section{F118}

Hay dibujada una " $A$ ", rodeada por un círculo que casi se cierra por la parte inferior. Es la forma de emplear letras europeas para representar: amén, que hasta ahora no había aparecido.

\section{F119}

Un rostro (círculo con ojos y boca está rodeados de puntos; representa la idea de: Jesús, con diferente dibujo que Jesucristo (F003).

Los cuatro pictogramas últimos constituyen la doble conclusión del formulario, que hasta este momento no había aparecido completa: asi [se] haga; amén Jesús.

El conjunto de la presentación de los mandamientos de la Iglesia arroja este resultado: Etesia son cinco., (..), El primero, misa oir ftos] domingos y fiestas. El segundo confesar el pecado totos tos años por Pasena una vez con dolor; su nombre, confesión. E1 tereere, reibir elerpo-[de] Jesucristo, [su] nombre, comunión. (Es su nombre comunión). El cuarto, ayunar [cuando] manda [la] madre Iglesia. El quinto, pagar [cada] diez; [su] nombre, diezmos. Son [los que] guardan, ven [los] santos vivos (...?) [que] hacen la unión, [su] nombre sagrado anuncio. Así [se] haga; amén Jesús. 


\section{PARTE TERCERA: SACRAMENTOS (F120-F166)}

Todo lo relativo a la presentación de los sacramentos está completo, sin fallos, ni carencias. Como sucede en otros catecismos pictográficos, el presente se limita en la práctica a un formulario, carente de explicación, porque no se puede llamar propiamente explicación a un pictograma que ofrece plásticamente el hecho del sacramento, y al que se añade cuál es su nombre. En los más breves catecismo no pictográficos, lo único que se enseñaba sobre los sacramentos eran sus nombres, carentes totalmente de explicaciones. Es casi con exactitud lo que se hace aquí.

\section{F120}

El guía porta en su mano una cruz. El sentido puede ser: creo.

Más adelante, en los artículos de la fe aparecerán dos pictogramas que se vinculan, el guía en uno y la cruz en otro; en esta ocasión, se funden ambos en un solo dibujo, como ocurre también en F409.

\section{F121}

Igual a F005: mano con cruz, que se traduce por: estos son.

F122

Un rectángulo lleno de puntos dispuestos en cuatro columnas. En la parte superior tiene una cruz, de remate; en la inferior una especie de corazón, con dos líneas hacia los lados. No tiene semejante en el catecismo. Podría entenderse como: divinos.

\section{F123}

En el centro hay una figura como una custodia, con una cruz en el centro, rodeado de rayos; otra cruz en la parte superior, y un soporte formado por dos triángulos. A los lados aparecen, arrodillados, dos personajes en actitud de adoración ( $i$ ángeles pues tienen alas?); sus aureolas respectivas son diversas una de otra, pero ambas denotan su carácter sacro. Vuelve a aparecer en F263.

Quiere decir: sacramentos.

\section{F124}

Igual a F066, conservando el mismo sentido: madre.

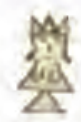

F125

Un edificio, con una sola cruz, parecido a F074 y F094, aunque no esté flanqueado por línea punteada. Muestra la idea de: Iglesia.

F126

Igual que F121 (aunque se vea sólo en parte), equivale a: son. 
F127

Una hilera de siete círculos constituye el numeral: siete.

\section{F128}

Un sólo punto denota el ordinal: el primero.

F129

Una gran jarra (la desproporción es evidente), inclinada, aunque nadie la sostenga, echa agua sobre el personaje del guía, que está situado debajo. Es obvio: echar agua.

F130

Igual a F086, conserva su valor: nombre.

\section{F131}

Sobre una base triangular aparece un recipiente cuyos lados se curvan en la parte superior. Si se entiende como un recipiente, el interior estaría lleno de agua (representada por hileras de puntos, como aparecían también en F129). El recipiente está cerrado por arriba con una tapadera rematada en una cruz. Solía ser ordinario que las pilas bautismales se mantuvieran así. El sentido, pues, no ofrece dudas: bautismo.

F132

Son dos círculos, que refieren el ordinal: el segundo.

F133

Pictograma que aparece fragmentario, por estar situado en el extremo inferior de la hoja. Sólo se percibe al guía, ante el cual hay una cruz en un mástil alto. Hay algo más dibujado a la derecha, pero está perdido. Podría entenderse como: ungir.

\section{F134}

Como el pictograma F086, con el mismo sentido: nombre.

\section{F135}

La figura del guia tiene en la frente una cruz, por la unción que ha recibido en el sacramento, por detrás, desde la cabeza a los pies cae una especie de larga cabellera, dibujada como una línea quebrada, como la que aparece después en F215. El pictograma significa: confirmación.

\section{F136}

EI ordinal aparece con tres círculos: el tercero. 


\section{F137}

Hay una figura parecida al guía, con la cara vuelta de frente. Tiene la cabellera al viento, que termina en un penacho curvo; a su espalda hay dos bolas de espino, punzantes. Como sucede en otros pictográficos, significa: padecer.

\section{F138}

Como F086, significa: nombre.

\section{F139}

Aparece dibujado un flagelo, con un mango en forma de bola a la izquierda, y cuatro correas que terminan en bola a la derecha. Un instrumento así era usado por los penitentes. De ahí su valor de: penitencia.

\section{F140}

Son cuatro los círculos en hilera; es el ordinal: el cuarto.

\section{F141}

Aparece el guía, carente de cualquier otro signo. El contexto sugiere que lo que corresponde aquí sería: recibir.

\section{F142}

Un círculo grande acoge en su interior el busto del dibujo que representa a Jesús. Es la forma de representar la hostia consagrada. Se ha de entender como: cuerpo, hostia.

Conviene recordar que después de F087 faltan pictogramas que mostrarían el tercer mandamiento de la Iglesia, que consiste precisamente en recibir el cuerpo de Jesucristo.

\section{F143}

El mismo pictograma que en F002, expresa la idea de: Señor.

\section{F144}

Igual que F003, ha de entenderse como: Jesucristo.

\section{F145}

Reproduce F086, y equivale a: nombre.

\section{F146}

Pictograma compuesto: sobre una " $A$ " mayúscula, aparece dibujado el pictograma F065, que solo, significa como, asi como. Pero aquí al hilo de la presentación de los sacramentos, corresponde el sentido de comunión (apenas se utilizaba la palabra eucaristía). 
No hay más remedio que recordar que en F091 y F094, a dos pictogramas les he atribuido ese mismo significado de comunión, si bien los dibujos eran totalmente diferentes a éste F146. Este pictograma, por sí sólo, sin atender al contexto, resultaría indescifrable.

F147

Se trata del ordinal: el quinto.

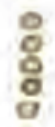

F148

Aparece sólo un busto, de frente, sobre un recipiente (?), como el de F034; todo está sobre un soporte triangular. El sentido, por el discurrir del formulario, es: enfermo, moribundo.

\section{F149}

El guía tiene la cabeza señalada por tres cruces en torno a ella, como consecuencia de haber sido ungido. En la idea - no enteramente en la plástica - se parece a F 133 , por dibujar una cruz, para el hecho de ungir. Cambia, por tanto, el dibujo, aunque no el sentido: ungir.

\section{F150}

Hay un pequeño círculo cuya mitad inferior está coloreada; sobre él hay una cruz, El equivalente es: Santo,

F151

Igual al pictograma F086, conserva su valor: nombre.

\section{F152}

El pictograma es un rectángulo con los extremos curvados, a la derecha se ve una especie de persona, con una serie de puntos alrededor de la cabeza. Podría ser contemplado como la imagen de un enfermo encamado, en vista cenital. El pictograma es: extremaunción.

F153

Seis círculos precisan el ordinal: el sexto.

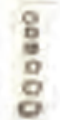

\section{F154}

Como si se tratara del guía, aparece un personaje con sombrero de tres picos, bonete. Se evoca la imagen de F025 (Padre), no sentado, sino de pie. El sentido también recibe un desplazamiento, pues de Padre (persona de la Trinidad), se pasa a padre, equivalente a sacerdote.

\section{F155}

Igual que F086: nombre. 


\section{F156}

Sobre un pedestal triangular, hay un rectángulo con dos hileras de puntos (como si se tratara de escritura?); tiene los ángulos adornados con volutas y una cruz en la parte superior. El pictograma sigue el hilo de los sacramentos: orden.

\section{F157}

Igual que F114, conserva su valor: sagrado

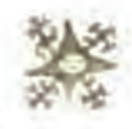

F158

Reproduce el pictograma F005: es.

F159

Siete círculos en hilera son el ordinal: el séptimo.

F160

Un hombre y una mujer unen sus manos, sobre las que está dibujada una cruz. El sentido es obvio: hombre y mujer unidos.

F161

Igual que F086, señala el nombre del sacramento: nombre.

F162

Extraño pictograma: sobre la cabeza del guía hay un animal, cuya cabeza se parece a la del conejo o liebre tantas veces representado y que figura también en el pictograma siguiente; pero tiene un cuerpo alargado con abultamientos en la espina dorsal. A pesar de tan impensado dibujo, el sentido ha de ser: matrimonio.

F163

Igual que F065, el mismo animal representa el valor: asi.

F164

Lo mismo que F006, se interpreta como: hacer.

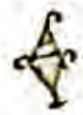

F165

El mismo pictograma que en F118, si bien el círculo externo esté deformado: amén.

F166

Como en F119, representa la idea de: Jesús.

A continuación, sin numeración como pictograma, aparece ocupando toda la altura de la banda, una separación formada por dos líneas paralelas, unidas entre sí por 
una línea quebrada entre ellas. Esta separación está mucho más clara que la que habia a continuación de $\mathrm{F} 074$; y volverá a aparecer más adelante en otra ocasión.

La parte que corresponde a los sacramentos queda completamente nítida, y en conjunto éste es su valor:

Crea [que] estos son [los] divinos sacramentos [de la] madre Iglesia; son siete. El primero, echar agua, [su] nombre, bautismo. El segundo, ungir: [su] nombre, confirmación. El tercero, padecer, [su] nombre, penitencia. Elcuarto, recibir [el] cuerpo [del] Señor Jesucristo; [su] nombre, comunión. El quinto, [al] enfermo ungir [con] Santo (óleo?): [su] nombre, extremaunción. El sexto, [ser] sacerdote; [su] nombre, orden sagrado es. El séptimo, hombre y mujer unidos; [su] nombre, matrimonio. Así se haga; amén Jesús.

\section{PARTE CUARTA: EXPLICACIÓN NO IDENTIFICADA (F167-F285)}

La parte cuarta de este catecismo pictográfico resulta un verdadero rompecabezas. A ello contribuyen varias razones. La primera es que no se trata de un formulario habitual, que transmita una oración o una enumeración de afirmaciones (mandamientos, sacramentos, ...) que formen un conjunto. La segunda razón es que también aquí falta al menos una hoja, con lo cual se interrumpe el hilo de la narración y quedan mutiladas las afirmaciones que aparecen en la parte conservada. La tercera razón es que precisamente esa parte conservada contiene pictogramas muy genéricos (por ejemplo, el "guía") en numerosas ocasiones, y apenas permiten una aproximación sobre lo que pudo contener esta parte cuarta.

Parece que hay que descartar enteramente que se trate de preguntas y respuestas, que, cuando aparecen, no siempre resultan fáciles de interpretar, por no percibir con nitidez cuál es su principio y su final. Pero no es este el caso.

En consecuencia, el intento de traducción queda forzosamente mutilado e incompleto, sin poder averiguar exactamente qué enseñanza transmitia. Pareceque se puede afirmar que se centra en la persona de Cristo, aunque al principio podría pensarse en afirmaciones sobre la Trinidad, especialmente por el pictograma F168, que, aunque mutilado, podria sugerirlo. Pero no hay apenas referencia al Padre ni al Espíritu Santo, por lo cual esta interpretación puede descartarse.

\section{F167}

Está la figura del guia, sin ningún complemento. Podría equivaler a: el. 
F168

El pictograma está incompleto en su parte inferior, pero en lo conservado se ven tres círculos iguales rematados por sendas cruces. Como he indicado podría referirse a la Trinidad, pero por la ausencia de las figuras del Padre y del Espiritu, es preferible descartar este sentido, y elegir el de: muy Santo.

Los tres dibujos de este pictograma son idénticos al del F150, que puede interpretarse también como santo, que evoca el óleo. Este adjetivo santo, está en cierto modo sustantivado, para referirse a Dios, el Santo por antonomasia. Por eso no emplea el pictograma F048, que se refiere a los santos padres, seres humanos modélicos, que han llegado a participar de la santidad de Dios.

F169

Igual que F026, con el valor de: Dios.

F170

Un círculo, que representa el numeral: un, uno.

F171

Igual que F150, es la expresión de: Santo.

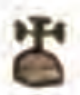

F 172

Lo mismo que F026, expresa: Dios.

F173

La persona del guia, difícil de descifrar, porque le sigue un pictograma casi enteramente desaparecido, que no es posible identificar: ?

F174

De nuevo aparece el guia ante el cual hay casi un círculo, formado por dos arcos que no llegan a cerrarse; en el interior hay un punto central. Representa un ojo. Y el pictograma cabría interpretarlo como: ve.

F175

Un circulo, que representa al numeral: uno.

F176

Igual que F150, con la idea de Santo.

\section{F177}

Lo mismo que F026, expresa: Dios.

F178

La figura que consta es la del guía, sin complemento alguno: $e l$. 
F179

En la parte central está el busto que representa a Jesús (parecido a F003). Le envuelve por los lados y por debajo un amplio arco, adornado con rayos hacia el exterior. Esta forma de representar lleva a pensar en que la equivalencia puede ser: bendito Hijo, o bendito

Jesús.

F180

Como aparecía en F022, al hablar en el credo de que subió al cielo, representa el segundo término: cielo.

\section{F181 y F182}

En principio ambos pictogramas están numerados por separado, por la distancia entre ellos, parecida a la habitual entre pictogramas. Una segunda consideración me ha llevado a unirlos en cuanto al sentido, como sucede en F174, y después en F188. Su sentido es: ve.

F183

Hay en el pictograma un cuadrado, cuyas esquinas están recortadas y (92) levemente coloreadas; determinan un rombo interior, con una cruz. Además, en el lado derecho aparece adosada la letra " $A$ ". El pictograma representa: tierra.

No percibo qué añade la "A" al pictograma.

\section{F184}

Igual a F033, con la equivalencia de: todo. HH

F185

Repetición de F179, con el mismo valor: bendito Hijo.

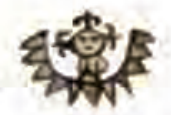

F186

Solo está la figura del guía, que puede equivaler a: el, el que.

F187

Lo mismo que F005, con el valor de: es, este es.

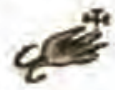

F188

Se repite F174, y F181-F182; equivale a: ve.

F189

Lo mismo que F006, se mantiene su sentido: hace. 
F190

Igual que F181, significa: cielo.

F191

Igual que F188, expresa la idea de: ve.

F192

El mismo pictograma F189, aunque sin la adición de la "A": tierra.

F193

El guía aparece con un rosario de cuentas en las manos, como en F001. Es la expresión de: rezo, ruego.

F194

Un círculo pequeño, como numeral, o más bien como adjetivo: único.

F195

Como F150, es el mismo pictograma, que significa: Santo.

F196

Repetición del pictograma F026: Dios.

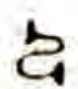

F197

Aparece únicamente el guia: el, el que.

F198

Igual que F005, con el valor equivalente de: es.

F199

Se repite la secuencia anterior; en este caso un círculo solo: un, único.

F200

Como F150. Representa: Santo.

F201

Repite F026, como equivalente a: Dios,

F202

Lo mismo que F005: es.

F203

Hay dibujado un pequeño cuadrado, que no está cerrado por la parte inferior, sino que tiene dos pequeñas curvas que se repliegan; tiene como 
si se tratara de dos patas a los lados y encima está coronado por una cruz, habitual. Su significado es: es engendrado.

F204

Como el pictograma F009, su valor es el de: madre.

F205

Figura solamente el guia: el, el que,

F206

Aunque levemente mutilado el pictograma, se ve que es idéntico a F005: es.

F207

Se repite el pictograma F203: es engendrado.

F208

Igual que F009, significa: madre.

F209

Es la figura del guía, sin ningún añadido: el, el que.

F210

Lo mismo que el pictograma F026, su valor es el de: Dios.

F211

El pictograma esta dañado por estar en la parte inferior externa. Pero se ve lo suficiente para asignarle sentido, pues aparece la cabeza coronada y de perfil de F004 y de F025. No cabe, pues, duda sobre su sentido: Padre.

F212

Es la misma representación que F003, con el mismo valor: Jesucristo.

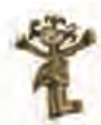

F213

La figura del guía, con el valor de: el, el que.

F214

Como el pictograma F011, aunque carece de las bolas espinosas que aparecian allí, Significa: Maria.

Aquí se interrumpe de nuevo el texto porque falta al menos una hoja (dos páginas), y la lectura de las bandas continuas queda incompleta. A partir de lo que se conserva en el f. $6 \mathrm{v}$, aunque no se siga una lectura fluida, es posible entrever que el texto se ha centrado en la actuación de Jesús, en los acontecimientos centrales 
de su muerte, resurrección y glorificación. Para ello, la ventaja es haber contado con el desarrollo del credo, que, aunque mutilado en su comienzo, está íntegro en esta parte. Por consiguiente es relativamente fácil seguir el avance del texto y casi suplir los pictogramas no existentes. Con el mismo procedimiento empleado, propongo el texto que aparece y el que hay que suponer por lógica:

\begin{tabular}{|c|c|}
\hline f. $6 \mathrm{v}$ & Hoja que falta \\
\hline $\begin{array}{l}\text { F212 Jesucristo / F213: el / F214: } \\
\text { [de] Maria }\end{array}$ & $\begin{array}{l}\text { nacido por el Espiritu-Santo, } \\
\text { fibre }\end{array}$ \\
\hline $\begin{array}{l}\text { F215: demonio / F216: Maria / } \\
\text { F217: virgen }\end{array}$ & padecio poder fdef Pilato \\
\hline $\begin{array}{l}\text { F218: crucificado / F219: muerto / } \\
\text { F220. sepultado }\end{array}$ & descendió at infierno falf tereer dia \\
\hline $\begin{array}{l}\text { F221: resucitó / F222: glorioso / } \\
\text { F223: de entre }\end{array}$ & tosmuertos subió atcieto \\
\hline $\begin{array}{l}\text { F224: está sentado / F225: a la } \\
\text { derecha / F226: del Padre }\end{array}$ & todo hacedor descteaffi \\
\hline $\begin{array}{l}\text { F227: bajará / F228: para / F229: } \\
\text { juzgar }\end{array}$ & tortos vivos ymuertos \\
\hline
\end{tabular}

F215

Una figura de perfil, con cuernos, que lo identifican como demonio, y proporcionan su sentido. Desde la cabeza le cae por la espalda una especie de cabellera larga hasta más abajo de la cintura, dibujada por una línea quebrada (semejante a la que aparece en F135). En su mano tiene una vara rematada en una bola espinosa, que en los pictográficos suele representar el mal, el dolor. Su sentido es bastante obvio, aunque no se mencione en el desarrollo del credo, como sucede aquí: demonio.

Precisamente por eso, hay que suponer que el pictograma anterior, no existente habría de ser libre, exenta.

F216

Igual que F011, representa a: Maria; las dos bolas espinosas señalarían: sin dolor, sin culpa.

F217

Igual que el pictograma F012 (se repite la misma secuencia): virgen. 
F218

Es igual que F014, conservando su sentido: crucificado.

F219

Como F015, pues continúa la sucesión similar al credo: muerto.

F220

En el pictograma hay dos personajes de perfil, con el rostro vuelto; portan unas angarillas sobre las que hay una caja con la consabida zruz en la parte alta. El sentido es muy claro: sepultado.

F221

Como F018, con la diferencia de que aquí aparece completo el pictograma: resucitó.

F222

Es pictograma muy parecido a F019, aunque en esta ocasión el personaje aparezca con corona de potencias a los lados de la cabeza, y no son simples rayos. El sentido es: glorioso.

F223

Aparece una " $A$ ", con un adorno a la derecha, parecido a F020; aunque el adorno de ambos pictogramas sea diferente, no cambia su equivalencia: de entre.

F224

Es igual que F023, conservando el valor: sentado.

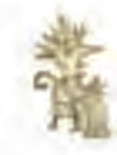

F225

Como F024, tiene el mismo sentido: a la derecha.

F226

Repite el pictograma F025: Padre.

F227

Pictograma dañado, por su posición en la hoja. Se ve una cabeza que mira de frente y a la derecha una mano. Pero comparado con F028, se somprueba que es idéntico: bajará.

F228

El guía, como en la secuencia correspondiente al credo (F030), significa: Dara. 


\section{F229}

Exactamente igual que F031, equivale a: juzgar.

La otra cara de la hoja que falta, frontera al f. $7 \mathrm{r}$ resulta más difícil de suplir, o de sospechar, porque los pictogramas que aparecen en el $\mathrm{f} .7 \mathrm{r}$ no permiten seguir un hilo narrativo con facilidad. Al no tratarse de un formulario conocido, sino de una explicación más amplia no es sencillo dar con su sentido. El cuadro que sigue constituye un anticipo de la descripción de los pictogramas que van desde F230 hasta F247, pero se ve claro que la falta de los pictogramas de la hoja desaparecida mutilan en gran manera la comprensión de la parte que ha subsistido, que resulta poco inteligible.

El cuadro que podría arrojar luz en este punto queda asi:

\begin{tabular}{|c|c|c|}
\hline \multicolumn{2}{|r|}{ Hoja que falta } & f. $7 \mathrm{r}$ \\
\hline \multirow[t]{6}{*}{ todos } & los vivos $y$ & $\begin{array}{l}\text { F230: muertos / F231: el que / F232: } \\
\text { es }\end{array}$ \\
\hline & & $\begin{array}{l}\text { F233: desde alli/ F234: los vivos / } \\
\text { F235: de corazón }\end{array}$ \\
\hline & & $\begin{array}{l}\text { F236: el que / F237: cuerpo(?) / } \\
\text { F238: padres }\end{array}$ \\
\hline & & $\begin{array}{l}\text { F239: cielo / F240: vida eternal } \\
\text { F241: es santa }\end{array}$ \\
\hline & & $\begin{array}{l}\text { F242: ruego / F243: a los santos/ } \\
\text { F244: ruego }\end{array}$ \\
\hline & & $\begin{array}{l}\text { F245: demonio / F246: demonio / } \\
\text { F247: el (?) }\end{array}$ \\
\hline
\end{tabular}

\section{F230}

Igual que F021, equivale a: muertos.

\section{F231}

Aparece el guía con un sentido muy genérico: el, el que.

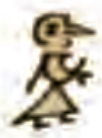

F232

Como F005, se puede entender como; es.

F233

Reproducción de F028, con el sentido de: desde alli. 
F234

Igual que F034, tiene el valor de: vivos.

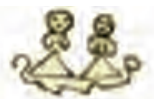

F235

Es réplica del pictograma F069, que representa: corazón.

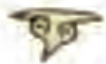

F236

Aparece la figura del guía; se puede ver como: el.

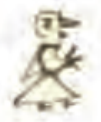

F237

Extraño pictograma. Se parece a F142 en que hay una figura en el interior de un círculo; pero se diferencia en que no es la misma figura, que entonces era la figura de Jesús, de frente y con potencias alrededor de la cabeza, y ahora es una figura de perfil, con rayos pequeños en torno a ella. No es posible cotejarlo con uno de los pictogramas de las hojas desaparecidas, que expresaba que había que recibir el cuerpo de Jesucristo, para cumplir con el precepto de comulgar. Parece que es el significado que se le podria atribuir: cuerpo.

F238

Como el pictograma F049, aunque aquí propone la idea de: hombres.

F239

Igual que el segundo término del pictograma F022 y que los pictogramas F180 y F190, representa: cielo.

F240

Es un dibujo parecido a F056, con la diferencia de que está orientado en sentido horizontal, y los adornos de los extremos no son iguales. Si entonces le asigné el sentido de: vida, vida eterna. Aqui, a continuación de la idea de cielo, también podría corresponder ese sentido, junto con el pictograma que sigue.

F241

El dibujo de la mano, que suele portar una cruz, en esta ocasión 1leva una silueta constituida por pequeños arcos, como la que ha salido en varias ocasiones desde el pictograma F048. Recuerda la representación de F067, en que una mujer llevaba el mismo signo en su mano. Podría ser: son santos.

F 242

Como F001, tiene la misma equivalencia: rezo, ruego.

F243

Repite el pictograma F048, que se entiende como: santos. 


\section{F244}

Se repite el pictograma F242: rezo, ruego.

F245

El dibujo sería igual que la persona del guía, habitual, pero sobresalen dos cuernos de su cabeza. Es claro que se trata del: demonio.

\section{F246}

De nuevo, a continuación del pictograma anterior, como reforzando la idea, aparece el demonio, también con cuernos, y con un rabo que le asoma por debajo del vestido, hacia la izquierda. El pictograma anterior lo representaba de perfil, mientras que éste lo hace de frente. Significa: demonio.

\section{F247}

Pictograma ilegible, en que aparece la parte superior del guía, sin nada especial. No es fácil asignarle significado alguno.

Tras la carencia de la hoja ya indicada, prosigue el catecismo y la enumeración de los pictogramas.

F248

Una figura como el guía, pero que tiene la cara vuelta, mirando de frente. Por faltar los pictogramas anteriores, no es fácil dar con un sentido cabal.

F249

Igual que el pictograma F021, su valor es: muertos.

F250

Pictograma que repite F016, aunque en esta ocasión el monstruo infernal haya sido dibujado sin dientes en sus mandíbulas. Expresa: bajó al infierno.

\section{F251}

De nuevo se repite el pictograma F021, con el sentido de: muertos.

F 252

Igual que F074, es posible asignarle el valor de: ve.

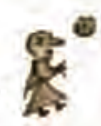

F253

El mismo pictograma que F048, significa: santos.

F254

Es idéntico al pictograma F137, por lo que equivale a: padecer.
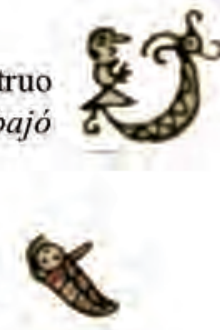
F255

Aparece en el centro del pictograma el busto del demonio, con los consabidos cuernos; le rodea una doble fila de pequeños arcos que diseñan una especie de aureola, para resaltar su importancia: demonio.

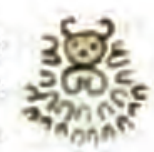

F256

Lo mismo que F005, y se puede entender como: estos son.

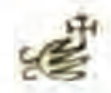

F257

Réplica del pictograma F049, con el valor de F238: hombres.

F258

Aparece el pictograma del guia; su valor en esta ocasión sería la conjunción:

que; o el pronombre: los que.

F259

La misma figura de F021 está representada con el mismo sentido: muertos.

F260

El mismo pictograma que en $\mathrm{F} 002$, con la diferencia de que el rasgo que brota a la izquierda de la base de la cruz, en esta ocasión da la vuelta y completa una circunferencia, por lo que en parte este pictograma se parece a F002, como está indicado; pero por otra parte es semejante a F171. El sentido puede ser la fusión de ambos pictogramas: Santo Señor.

F261

Igual que el pictograma F002, se ha de entender como: Señor.

F262

Igual a F026, es la expresión de: Dios.

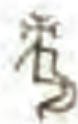

\section{F263}

Salvo detalles insignificantes, es igual que el pictograma F123, y equivale a: sacramentos.

\section{F264}

Es la figura del guía, que expresa: el, el que.

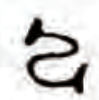

F265

De nuevo aparece el guía, pero a diferencia del pictograma anterior, tiene una línea curva dibujada a la altura de su boca. Puede expresar: dice. 
F266

Es idéntico al pictograma F043, que representa: Iglesia.

F267

Hay un raro pictograma, con una única aparición: una figura alargada, con rostro humano y un cuerpo alargado y curvo, tiene la cabeza y el cuerpo rodeado de pequeños rayos que lo aureolan. La cabeza y la parte superior que correspondería al torso reposan horizontales sobre un apoyo constituido por dos círculos, mientras que el resto del cuerpo cae hacia la izquierda. Por la posición del dibujo cabría pensar que equivale a: cadáver (?).

F268

Aparece la figura del guia, sin que sea sencillo dar con algùn significado.

Quizá: de.

F269

Un círculo representa el adjetivo: uno, único.

F270

De nuevo se repite la figura del guía en este pictograma.

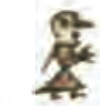

F271

El dibujo es igual que F046, con la idea de: unión.

F272

De nuevo está a la vista la figura del guia; podría evocar aquí la preposición: de.

F273

Se repite el pictograma F033, con el valor de: todos.

F274

Pictograma compuesto. A la izquierda, la misma representación de F025, equivale

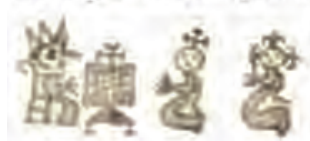
a: Padre. Sigue un soporte con un libro (la escritura está representada por puntos alineados); sobre él hay una cruz. A la derecha, una figura arrodillada, con una cruz sobre la cabeza comparece ante él. Más a la derecha (cabe pensar si se integra en el mismo pictograma, o son dos diversos), aparece la figura del Hijo, con corona de potencias, como en otras ocasiones (F179). El conjunto podría entender como: los que ante el Padre confiesan al Hijo.

F275

Pictograma igual a F002, su sentido es: Señor.

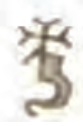


F276

Pictograma dañado: sólo se ve la parte superior, que se parece (pero no se identifica) con el pictograma anterior: Señor (?).

Es repetición de $\mathrm{F003,} \mathrm{y} \mathrm{equivale} \mathrm{a:} \mathrm{Jesucristo.}$

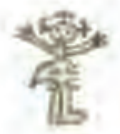

F278

Lo mismo que F005, se ha de entender como: es,

F279

Lo mismo que F171, corresponde a la idea de: Santo, acaso cuadre mejor: santificados.

F280

Hay dibujada una simple cruz, potenzada, como siempre. El pictograma se repite más adelante, $\mathrm{y}$ en todas las ocasiones tiene la equivalencia de: creo.

F281

A pesar de estar dañado en la parte inferior, se ve el pictograma igual a F049: hombres.

F282-F285

Igual que F163-F166, corresponden a la conclusión: Asi [se]

haga; amén Jesús.

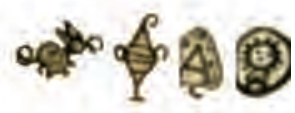

A continuación de este pictograma, hay una división vertical en la banda, que consiste en dos líneas verticales entrelazadas por una línea quebrada que va de una a otra. Marca la separación entre partes del catecismo, y no la he numerado como pictograma.

El formulario de esta parte cuarta, es largo. Además, resulta poco conocido y no corresponde a ninguno de los habituales, y hay que estimarlo más bien como una explicación. No es fácil dar con su sentido en todas las ocasiones: hojas que faltan, pictogramas que aparecen sólo una vez, pérdida de sentido. Si se aprecia que en un momento determinado deriva hacia una presentación de la trayectoria de Jesús para la salvación humana. Y hacia el final aparece la idea de una valoración o juicio que Dios ha de hacer de las personas, para decidir su suerte eterna.

El conjunto del desciframiento, con las lagunas indicadas, podría quedar así: El muy Santo Dios, un Santo Dios que (...) ve; un santo Dios, el bendito Hijo el cielo ve y la tierra toda. El bendito Hijo que este es, ve [y] hace el cielo, ve la tierra. Ruego al único Santo Dios, el que es único Santo Dios, fue engendrado [de 
una] madre, el que fue engendrado [de una] madre [por] el Dios Padre; Jesucristo, al que Maria.... nacido per el Espiritu Santo, libre [del] demonio Maria sin culpa, virgen, padeciófpor fpoder [de] Pitato crucificado, muerto [y] sepultado; descendió al infierno fal] tercer dia resucitó glorioso de entre tos muertos, subrió at cieto, está sentado a la derecha del Padre todo hacedor. Beste atlf hajará para juzgar [a] totos vivos y muertos. El que es (...) desde alli los vivos de corazón (...) el que cuerpo [de los] padres (...) cielo [la] vida eterna(?) es santa (...). Rezo a los santos, rezo (...) demonio, demonio ... ... muertos bajan al infierno. [Los] muertos [que no] se ven santos padecen [con] el demonio. Estos hombres [que] mueren [por el] Santo Señor, Señor Dios, [con los] sacramentos. Lo dice [la] Iglesia: el cadáver [de] uno, la unión de todos los que confiesan ante el Padre al Hijo [como] Señor, Señor (?) Jesucristo. Estos son santos como [los] creen [los] hombres. Asi se haga, amén Jesús.

\section{PARTE QUINTA: ARTICULOS DE LA FE (F286-F426)}

La parte que sigue, la quinta, la constituye el formulario de los artículos de la fe. Se trata de un formulario muy conocido, que tenía hondas raices medievales, con un evidente paralelismo parcial con el credo. En efecto, el formulario está constituido por dos septenas: la primera se dedica a la divinidad, con expresión de algunos atributos divinos que corresponden a las tres personas de la Trinidad; la segunda serie se dedica a los más relevantes momentos de la actividad de Jesús encarnado, donde no hay forma de evitar el paralelo con el credo apostólico, que habia aparecido en la primera parte del catecismo.

De esta forma, los pasajes más notables de la vida de Jesús aparecen en tres ocasiones en el catecismo, con una reiteración poco lógica. En muchos catecismos, pictográficos o no, era corriente que apareciera dos veces, una en el credo y otra en los artículos de la fe. En el presente catecismo, la explicación de la parte inmediatamente precedente lo incluye otra vez más, como si se tratara de no silenciarla por ningún motivo.

En esta parte, también vuelve a suceder el inconveniente de la carencia de una página intermedia, que mutila el sentido y deja titubeante el final del formulario, aunque pueda ser imaginado parcialmente.

El formulario tiene una extensa introducción antes de comenzar con los artículos propiamente dichos

\section{F286-F287}

Aparece el guía en el primer pictograma. En el segundo, la cruz, como

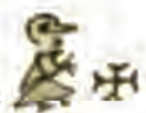
en F280. Aunque los he numerado por separado (por la distancia entre ellos que no permite hablar de pictograma compuesto), lo cierto es que la 
combinación de ambos se repite con una abundancia extraordinaria en este formulario. El conjunto de los dos pictogramas tiene el sentido global de: creo.

\section{F 288}

Lo mismo que F049, aquí corresponde mejor el sentido de: hombres.

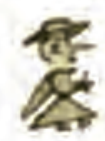

F289-292

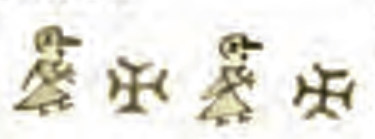

Figura dos veces la conjunción de los pictogramas con el guía y la cruz: la repetición seguida puede ser entendida como un subrayado, más que como un plural: creo, creo en verdad.

F293

Se repite el pictograma F002; corresponde a: Señor.

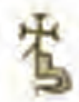

F294

Vuelve a aparecer F026, con el valor de: Dios.

F295

Es la figura del guía, que puede equivale, sin más a: el.

F296

Hay un solo círculo, como en otras ocasiones. Se ha de entender como el adjetivo: único.

F297

Se repite el pictograma F171, con su valor: Santo.

F298

Como el pictograma F027, se interpreta como: todo hacedor.

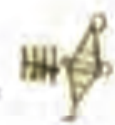

F299

La figura del guía tiene en su mano una línea quebrada. (Vuelve a aparecer casi igual en F373). Por coherencia con estas dos ocasiones, su valor es: salva.

F300

El pictograma muestra al guia que tiene en las manos una pequeña figura humana ( cabeza, ojos, boca). Parece que hay que interpretarlo junto con el pictograma anterior como: salva [al] hombre.

La figura del guía tiene en su mano el dibujo que aparecía en F048. 
Pero en F067, otro pictograma parecido mostraba una mujer con el mismo dibujo en su mano, y equivalía a mujer santa. Por lo tanto, en esta ocasión podría entenderse como: hombre santo, o quizá mucho mejor: santifica.

F302

Un solo círculo, como F296, sería, pues: el único.

F303

Es un pictograma extraño: en principio aparece la figura del guía (cabeza, cuerpo y pies de perfil); pero el torso está de frente y muestra los brazos (con una curva) rematados por manos estilizadas (otra curva pequeña). Consta más adelante (F441), y el sentido que mejor corresponde a este pictograma es: ama.

F304

La letra "A" mayúscula que ha aparecido otras veces, tiene a su derecha una voluta con doble curva, una por la parte alta y otra por la baja, que se repliegan. Parece corresponder el sentido de dirección: $a$, hacia.

\section{F305}

Se repite el mismo pictograma de F192, que equivale a: tierra.

F306-F307

Los pictogramas del guía y la cruz aportan el valor de: creo.

F308

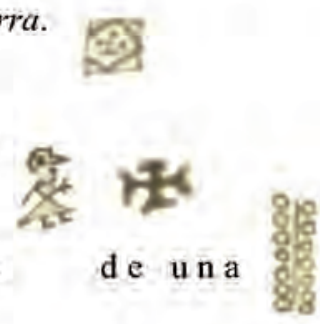

Hay dos hileras de círculos dispuesto en vertical a los lados de un a línea entre ellos. Se trata del numeral: catorce.

F309-310

El guía seguido por la cruz nos hablan de: creo.

F311

Se repite el pictograma F065; significa: así, asi como.

F312

Es la figura del guía: ha de interpretarse en femenino por los pictogramas que siguen: $l a$.

F313

Lo mismo que F171, tiene el valor de: santa.

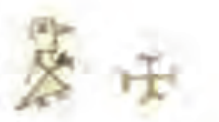

F314

Aunque levemente mutilado, aparece el mismo dibujo que F066: madre. 
F315

Como el pictograma F033, reproducido, significa: Iglesia.

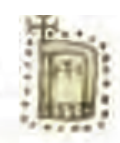

F316

Es igual que F005, y su valor es: estos, estos son.

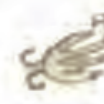

F317

Lo mismo que en F048, representa la idea de: santos.

F318

Repetición del pictograma F171, con el sentido de: Santo.

F319

El guía porta en su mano una cruz pequeña. Dado el valor asignado a la cruz, este pictograma podría equivaler a: cree.

F320

El pictograma representa al guía; podría equivaler a: por.

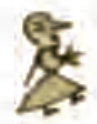

F321

Igual al pictograma F021, su valor es: muerto.

F322

Como el pictograma F001, con la diferencia de que a la espalda de éste hay dibujada una especie de ala, como en otras ocasiones. No parece alterar su significado: rezo.

F323

Como F280, aparece la cruz, conservando el sentido de: creo.

F324

Frente a la figura del guía está dibujado un cuadrado, relleno con
pequeños puntos; en la parte superior derecha el cuadrado tiene una
cruz; es parecido a F122, donde le asigné el valor de: divinos, como
adjetivo. Aquí junto con el pictograma siguiente, es posible que su

F325

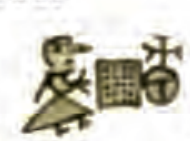

Este pictograma es muy parecido al anterior, pero se le añade a la derecha el mismo dibujo de F171. Como está indicado en el pictograma anterior, el sentido que parece corresponder seria: la figura del guía). mandamientos [del] Santo. (En F436 se repite aunque no aparezca 
F326

Como F005, se entiende como; estos, estos son.

F327

Igual a F171, se interpreta como: Santo.

F328

Es pictograma idéntico a F002, con su valor: Señor.

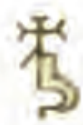

F329

Igual que el pictograma F026, expresa la idea de: Dios.

F330

Es réplica de F086, y conserva su sentido: nombre.

F331

Una "A" mayúscula, mayor que lo habitual, está adornada con puntos que recorren su silueta; a su derecha, aparece el mismo dibujo del pictograma F329. Su sentido ofrece pocas dudas: articulos [sobre] Dios.

F332

Un único círculo que representa al ordinal: el primero.

F333-F334

El guí, seguido de la cruz, tienen el valor asignado: creo.

F335

En único círculo, como F332, pero que aquí adquiere el sentido del adjetivo:

único.

F336

Igual que F171, su interpretación es: Santo.

F337

Como en F026, expresa la idea de: Dios.

F338

Calcado al pictograma F027, con el valor de: todo hace, todo hacedor.

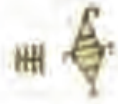

F339

Dos círculos en hilera vertical; es el ordinal: el segundo.

F340-F341

Los pictogramas del guía y la cruz, expresan: creo.

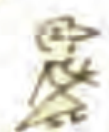


$\mathrm{r} 342$

Con el mismo significado que en el precedente F026: Dios.

\section{F343}

Se presenta el mismo dibujo que en F025, asignado a Dios: Padre.

F344

El ordinal aparece representado por tres círculos en hilera vertical: el tercero.

F345-F346

Son el guía, seguido de la cruz, con el valor de: creo.

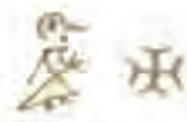

F347

Es idéntico a F026, y la idea que expresa es: Dios.

F348

La representación de Jesús, con la cabeza ornada con potencias a los lados y sobre ella. Su sentido inequívoco es: Hijo.

Si se compara este pictograma con F011, se comprueba que, salvo las bolas espinosas de la izquierda, los dibujos son idénticos. Pero el sentido en aquel lugar se referia, sin duda a María, virgen, mientras que aqui, al relatar los artículos de la divinidad, tampoco hay duda en entenderlo como Hijo, persona divina.

F349

Cuatro círculos en disposición vertical son el ordinal: el cuarto.

F350-F351

Aparecen el guía y la cruz; significan: creo.

F352

0
0
0

Como en F026, su valor es el de: Dios.

F353

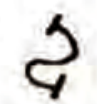

Se repite el pictograma F040, conservando su sentido unívoco: Espiritu Santo.

En este punto se produce una omisión del dibujante, el tlacuilo, que se olvidó de dibujar los cinco círculos que representaran el ordinal el quinto. Es una omisión evidente, porque en la banda anterior no habia sitio, y en esta banda última, a la izquierda de F354 hay espacio suficiente para que aparecieran al menos algunos círculos y que los de la zona inferior se hubieran perdido por deterioro, pero no existe vestigio alguno.

F354-F355

De nuevo son el guia seguido de la cruz potenzada, con el sentido: creo.

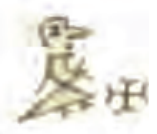


F356

Aparece el guía, que puede ser entendido como el simple artículo: el o un.

F357

Hay un círculo con el sentido de adjetivo, como en F335: único.

F358

Idéntico a F171, expresa la idea de: Santo.

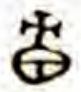

F359

Como en F026, su sentido es: Dios.

F360

Aunque mutilado en parte, el pictograma es reconocible como el F027: todo hacedor.

F361

Está dibujado el guía, ante el cual aparece un ojo; igual a F074, es: ve.

F362

Aparece un dibujo igual al de F083, algo más detallado, pues aparece más detallada la cola de la serpiente representada. Equivale, como entonces a: pecado.

\section{F363}

Se repite el pictograma anterior: el doble dibujo puede ser entendido como plural: pecados, o como subrayado: todo pecado.

\section{F364}

Se repite F361, con su mismo valor: ve.

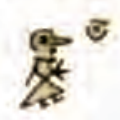

F365

Lo mismo que F033, tiene el sentido de: todo. III

F366

De nuevo aparece reiterado $\mathrm{F} 361$, conservando la equivalencia: ve.

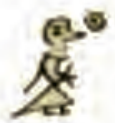

F367

Está dibujado el guía sin ningún típo de complemento, El significado que parece cuadrar en esta ocasión es genérico: hombre.

F368

Una hilera vertical de seis círculos representa el ordinal: el sexto. 
F369-F370

Son los dibujos del guía al que sigue el de la cruz: creo.

F371

Lo mismo que F026, trae la idea de: Dios.

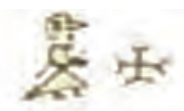

F372

Es réplica del pictograma F299, con su mismo sentido: salva.

F373

Reproduce a F300, y el valor es el mismo: salva al hombre.

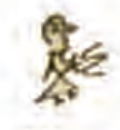

F374

Lo mismo que sucedía en F367, el sentido que le cuadra es el genérico: hombre.

F375

La hilera está formada por siete pequeños círculos: el séptimo.

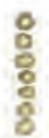

F376-F377

Guía y cruz aportan su equivalencia, tantas veces repetida: creo.

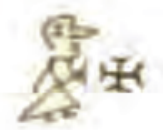

F378

Como F026, su valor ha de entenderse como: Dios.

F379

El guía aparece teniendo en la mano el mismo dibujo de F048, como estaba dibujado también en F301; y el significado asignado en aquel momento responde también a éste: santifica.

F380

Una mano con una cruz, como en F005, equivale a: estos, estos son.

A partir de este pictograma comienza la introducción de la segunda septena, la de los artículos relativos a la humanidad de Cristo.

F381

Siete círculos dispuestos en hilera representa el numeral: siete.

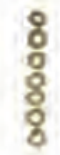

F382-F383

Equivalen a: creo, como en ocasiones anteriores.

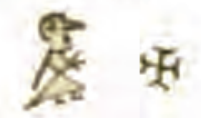

F384

Una cruz, de mayor tamaño que la del pictograma anterior, dibujada como 
cruz de Malta. Supone otra forma de representar la idea de artículos, no expresada con la " $\mathrm{A}$ " mayúscula, como en F331. O, si se prefiere, para variar el significado, puesto que cambia el dibujo, sería: afirmaciones.

\section{F385}

El guía da paso al pictograma siguiente: él.

\section{F386}

Es igual que F013, conservando su sentido: como hombre.

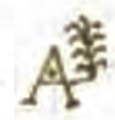

F387

Igual que F002, se entiende como: Señor.

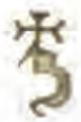

F388

Igual que F003, equivale a: Jesucristo.

F389

El mismo pictograma de F006, que significa: hace.

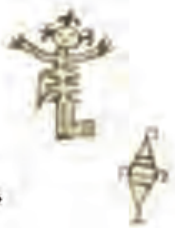

F390

El dibujo muestra una persona parecida al guía, pero con el rostro vuelto de frente, y la cabeza aureolada de rayos; puede significar: hombre

F391

El pictograma representa al guía: el.

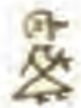

F392

Un círculo es el ordinal: primero.

F393-F394

La conjunción de ambos pictogramas expresa: creo.

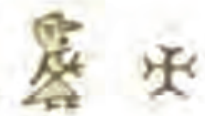

F395

Igual a F002, es la idea de: Señor.

F396

Repite el pictograma F003, es decir. Jesucristo.

F397

Repite el pictograma F006: hacer, hecho.

F398

Dibujo igual que el pictograma F047, se entiende por: hombre. 
F399

La cara, que corresponde a Jesús, tiene dibujada encima una cruz; está rodeada por un círculo completo y otro incompleto sólo por debajo, formados por pequeños arcos; todo ello, sobre un soporte. Evoca la imagen de F255, en que aparecía el demonio con los mismos círculos, como expresión de su poder. Aquí se trataría, por el contrario, del poder de Jesús.

F400

Con una representación diversa, aparece (casi se ve completa) la " $\mathrm{A}$ ", con una serie de pequeños arcos que rodean la letra por la parte superior. No veo claro el sentido que pueda tener.

F401

Igual a F026, significa: Dios.

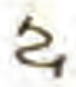

F402

Repite el pictograma F040, que representa al: Espiritu Santo.

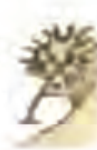

A partir del pictograma siguiente ( $\mathrm{F} 403$ ) de nuevo hay que moverse con extrema prudencia, porque la carencia por lo menos de una hoja (dos páginas) dejan interrumpida la lectura de cada banda, pues falta la media banda de la página frontera. Eso dificulta la fluidez. Sin embargo, la ventaja en este caso es que después de haber presentado los artículos de la fe relativos a la divinidad, sigue con la segunda septena, la de los referentes a la humanidad de Cristo, y en factible intuir lo que falta, sin tener que hacer aventuras imaginativas. Con esas limitaciones, prosigo el desciframiento de los pictogramas.

\begin{tabular}{|c|c|}
\hline F. $11 v$ & Hoja que falta \\
\hline $\begin{array}{l}\text { F401: Dios / F402: Espiritu Santol } \\
\text { F403: el segundo }\end{array}$ & $\begin{array}{l}\text { ereo fque ef] Sefior } \\
\text { festucristo }\end{array}$ \\
\hline $\begin{array}{l}\text { F404: fue concebido / F405: madre/ } \\
\text { F406: mujer }\end{array}$ & $\begin{array}{l}\text { virgen } f y\} \text { nacio de } \\
\text { tna }\end{array}$ \\
\hline $\begin{array}{l}\text { F407: mujer / F408: el terceral } \\
\text { F409: creo F410: Señor }\end{array}$ & fesucristo [fue]crucificado \\
\hline $\begin{array}{l}\text { F11: corazón / F412: muerto / F413: } \\
\text { guía }\end{array}$ & $\begin{array}{l}\text { Ipara] salvar peedores Et } \\
\text { etrarto }\end{array}$ \\
\hline F414-F415: creo/F416: Señor & festeristo bajoa tos infiernos fyt \\
\hline F417: enterrado / F418: ? /F419:? & restreitóglorioso \\
\hline
\end{tabular}


F403

Dos círculos, señalan el ordinal: el segundo.

F404

Es idéntico al pictograma F008, con el mismo valor: fue concebido.

F405

Repite F008 (incompleto), o F066 (completo): madre.

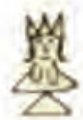

F406

El dibujo muestra de frente la figura de una mujer (cabello largo); F067 proponía una mujer, pero de perfil y un complemento en la mano. Éste podría equivaler únicamente a: mujer.

F407

De nuevo se repite el pictograma anterior, aunque entre ambos faltan los de la media banda desaparecida, que completarian el sentido: mujer.

F408

Tres círculos marcan el ordinal: el tercero.

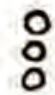

F409

El guía tiene en su mano la cruz, como en F120; se han fundido en un dibujo los pictogramas que aparecían por separado a lo largo de los artículos de la fe. Significa: creo.

F410

Lo mismo que F002, equivale a: Señor (intentaremos replicarlo)

F411

Igual a F069, es posible entenderlo como: corazón o también voluntariamente.

F412

Como F021, en esta ocasión le corresponde sentido verbal: murió.

F413

La figura del guía, carece de sentido sin su continuación

F414-F415

Tras los pictogramas que faltan, la figura del guía vuelve a aparecer junto con la cruz: creo.

F416

Lo mismo que F002, expresa la idea de. Señor. 
F417

Aunque mutilado en parte se ve que es idéntico a F220. No ofrece dudas: sepultado.

A diferencia de F220, en el actual pictograma se llega a ver la cabeza de una persona: que llevan a enterrar

F418

Pictograma único, parecido, aunque no completamente igual a F056. No encuentro sentido propio.

F419

Es igual a F248. Como en aquel caso, no se capta el sentido al faltar los pictogramas siguientes.

A partir de aquí faltarian tres o cuatro pictogramas en la última banda de la página que falta, y, vuelta esta, faltarían otros tres o cuatro en la primera banda de la página siguiente. En total, faltarían unos ocho pictogramas; pero habría que descontar dos, uno que representara el sexto y otro que expresara el séptimo. Quedarían seis pictogramas, a los que añadir los tres que figuran en la primera banda de la parte conservada (f. 12r). Total, nueve pictogramas, más los dos de la numeración.

Resulta difícil imaginar que con once pictogramas se hubiera podido expresar en el catecismo todo lo que expresa el formulario de los artículos de la fe en este punto: que «está sentado a la derecha del Padre», y que «vendrá a juzgar a los vivos y los muertos: a los buenos para darles gloria porque guardaron sus santos mandamientos, y a los malos pena porque no los guardaron». Precisamente tan prolongada explicación permite aventurar la sospecha de que acaso no falta una hoja en este punto, sino dos. Pero no hay forma de saberlo.

F420

Pictograma igual a F097, y muy parecido a F059: mandar.

F421

Comoel pictograma F002, expresa: Señor.

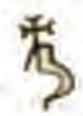

F422

Se repite el pictograma F026, con la idea de: Dios.

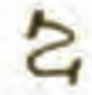

F423

Igual que el pictograma F073, es parte de la conclusión: asi.

F424

Como F006, con el valor de: haga.

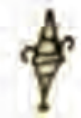


F425

Igual que F118, equivale a: amén.

F426

Repite el pictograma F074, significa: Jesús.

El resultado del desciframiento de los artículos de la fe, con las carencias indicadas, es:

Creo [con los] hombres; creo, creo en verdad [al] Señor Dios, al único Santo, todo hacedor, [que] salva, salva al hombre, [y] santifica, al único [que] ama a [la] tierra. Creo [los] catorce; creo asi como la santa madre Iglesia. Estos son santos, [que al] Santo creen; [por los] muertos rezo. Creo [sus] mandatos, mandamientos [del] Santo; estos son [del] Santo Señor Dios. [Su] nombre: articulos [sobre] Dios (o sobre la divinidad).

El primero, creo [en un] único Santo Dios todo hacedor.

El segundo, creo [en] Dios Padre.

El tercero, creo [en] Dios Hijo.

El cuarto, creo [en] Dios Espiritu Santo.

[El quinto], creo [en] un Santo Dios todo hacedor, [que] ve [el] pecado, todo pecado, [que] ve todo, [que] ve [al] hombre.

El sexto, creo [en] Dios [que] salva, salva al hombre. [a] todo hombre,

El séptimo, creo [en] Dios [que] santifica.

Estos son [las] siete [que] creo afirmaciones, de [el] como hombre Señor Jesucristo, hecho hombre.

El primero, creo [que el] Señor Jesucristo, [se] hizo ...hombre...) Dios Espiritu Santo.

El segundo ereo [que ef] Sefior Jesucristo fue concebido madre mujer virgen $[y]$ nació de una mujer.

El tercero creo [que el] Señor festeristo ffue]erteifieato, voluntariamente muerto [para] satvar [atos] pecatores:

Eteuarto creo [que el] Señor festreristo bajo a tos infiernos $[y]$ sepultado resucitó gtorioso.

...

[lo que] manda el Señor Dios. Asi se haga, amén Jesús.

\section{PARTE SEXTA: MANDAMIENTOS DE DiOS (F427-F494)}

Como ya he indicado, falta una hoja, cuyo vuelto daría pleno sentido al f. $12 \mathrm{r}$. A pesar de esta ausencia, especialmente por lo que sigue a continuación, es patente que lo que constituye esta parte son los mandamientos de Dios. Ya indiqué la extraña distribución proponiendo primero los mandamientos de la Iglesia (parte segunda) y luego los de Dios (parte sexta); pero así aparece. 
La carencia de la hoja precedente permite vislumbrar así el comienzo:

\begin{tabular}{|c|c|}
\hline Hoja que falta & f. $12 \mathrm{r}$ \\
\hline et séptimo... & $\begin{array}{l}\text { F420: que manda / F421; [el] Señor / } \\
\text { F422: Dios / F423: Asi / F424: [se] } \\
\text { haga / F425: amén/ F426: Jesús. }\end{array}$ \\
\hline $\begin{array}{l}\text { Estos son fpara los] creen [enet] } \\
\text { Señor-Pios }\end{array}$ & $\begin{array}{l}\text { F427: nombre/ F428: mandatos/ } \\
\text { F429: contra? / F430: demonio. }\end{array}$ \\
\hline & $\begin{array}{l}\text { F431: ?/ F432: tierral F433: estos/ } \\
\text { F434: son }\end{array}$ \\
\hline diez & $\begin{array}{l}\text { F435: nombre / F436: mandamientos/ } \\
\text { F437: el primero / F438: amar }\end{array}$ \\
\hline $\begin{array}{l}\text { fa] Dios [sobre] todas flas] cusas. Et } \\
\text { segunda }\end{array}$ & $\begin{array}{l}\text { F439: maldecir/ F440: blasfemar / } \\
\text { F441: enviado / F442; amar }\end{array}$ \\
\hline $\begin{array}{l}\text { Efterecro santificar [ef] } \\
\text { donimgo }\end{array}$ & $\begin{array}{l}\text { F443: Iglesia / F444: descanso hace / } \\
\text { F445: Hijo }\end{array}$ \\
\hline
\end{tabular}

Como es habitual, los mandamientos dan comienzo con una sucinta explicación o introducción global, que precede al enunciado breve de cada uno de los mandamientos. Precisamente esa introducción es la que se pierde fundamentalmente al conservarse sólo parte de los pictogramas.

Al concluir la primera banda del f. 12r con la expresión Así se haga; amén Jesús, no hay duda que en la banda segunda comienza este formulario. El pictograma F428, que representa la idea de bautismo (como en F131), me ha llevado a pensar que el comienzo podría ser: Estos son fpara los] ereen [encl] feñor fios.

F427

Es idéntico a F113, con la equivalencia de: nombre.

F428

La parte superior del pictograma, prescindiendo de la base sobre la que está instalada la pila, es igual a F131, que habla de: bautismo.

F429

Hay una espiral en la parte alta de la banda; no tiene paralelo. Con dudas, podría significar: contra?

F430

Es igual que F245 (el dibujante olvidó los pies). Significa: demonio. 
r451

Un personaje, el guía, tiene la cara vuelta al frente y porta una cruz alta. (En

F133 también aparece el guía con una cruz alta).

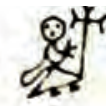

F432

Igual F192 su valor és el de: 1 tierra.

F433

El guía precede al pictograma siguiente; equivale a: éstos.

F434

Lo mismo que F005, conserva su sentido: son.

En algún lugar de la banda correspondiente, en la hoja desaparecida tendría que figurar el numeral diez.

F435

[déntico a F113, se interpreta como: nombre.

F436

Aunque no aparezca asociado a la figura del guía, el dibujo es igual a F325: mandamientos [del] Santo, o simplemente, mandamientos.

F437

Aparece el ordinal, representado por un único círculo: el primero.

F438

Junto al pictograma está, de frente, una persona con los mismos trazos que F303 (también le faltan los pies). El sentido del formulario reclama aqui el sentido de: amar.

En la media banda que sigue, tendria que figurar: $\{a]$ Dios $[$ sobre $\}$ todas tas] cosas. Et scgundo.

F439

De la boca del guía brotan palabras, representadas por puntos. Significa: hablar.

$\mathrm{F} 440$

El dibujo es prácticamente repetición del pictograma anterior. Ambos podrían entenderse como plural: palabras. O también, dichos $y$ palabras.

Como en los mandamientos no está expresada la forma negativa, que se sobrentiende (ver, por ejemplo el quinto mandamiento), aquí se podría también sobrentender: maldecir y blasfemar. 
F441

Como la figura del pictograma F303, tendria aquí el nuevo sentido de F438:

amar.

F442

Igual que F113, se entiende por: nombre.

Faltarían pictogramas que corresponderían a tercero, misa.

F443

El mismo dibujo de F074, que equivale a: Iglesia.

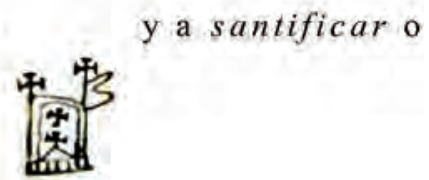

F444

Es pictograma compuesto: una persona divina (rayos en la cabeza, pero no sombrero de tres picos, como F025) aparece sentada y tiene en su mano el dibujo que corresponde a F006: hacer. Quizás hacer sentado pueda entenderse como descansar, reposo hacer.

F445

Idéntico a F348, con el sentido de: Hịjo.

F446

Como el pictograma F001, su valor es: rezo, rezar.

F447

Lo mismo que F171, equivale a: Santo.

F448

Pictograma ordinal: cuatro círculos: el cuarto.

F449

Lo mismo que el pictograma F174, la idea es: ver.

F450

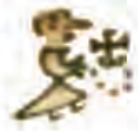

Pictograma compuesto de un hombre (como el guía, y una mujer (?), parecido a F072. El sentido lo proporciona con más exactitud el propio formulario: honrar.

\section{F451}

También es pictograma compuesto, con la figura del hombre que equivale a: padre, y la figura de la mujer, más nítida que en el pictograma anterior (como la figura del pictograma F067). No

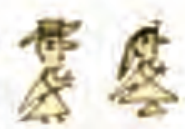
emplea el pictograma F007 (= madre), que lo reserva para María, madre de Jesús. El sentido, pues del pictograma, es: padre [y] madre. 
F452

La hilera de cinco círculos, vertical, muestra el ordinal: el quinto.

F453

Pictograma compuesto, en que aparece la figura del guía que tiene ante sí la imagen de un muerto. Se sobrentiende que es preciso marcar el sentido negativo: [no] matar.

\section{F454}

En esta ocasión son seis los círculos de la hilera: el sexto.

\section{F455}

Aparece una extraña figura, con el cuerpo de frente y la cara de perfil. Sobre la cabeza tiene dos exagerados adornos, como un tocado extravagante; en lugar de brazos aparecen unas alas. Todo el dibujo parece evocar un disfraz (carnavalesco?). Aunque sólo sale en una ocasión, el formulario deja claro el equivalente: [no] fornicar.

F456

De nuevo, como es lógico, aparece el número ordinal: el séptimo.

F457

La figura del pictograma F047 está dibujada mientras esconde a sus espaldas una bolsa repleta (dibujado por puntos). Es evidente su mensaje: [no] hurtar.

F458

Representa el ordinal con ocho círculos dispuestos en hilera: el octavo.

F459

Es idéntico a F439: hablar.

F460

Casi igual que el anterior, de la boca de la persona, además de palabras (puntos), brota una pequeña cabeza con minúsculos brazos curvos: mentiras.

Aparece la cara vuelta al frente, como en F246; tiene cuernos, como rasgos demoníacos (aunque carece de rabo, como en aquél y también de pies). Su equivalencia puede ser: mentiras.

F462

Los nueve círculos, dispuestos en vertical, dan el significado: el noveno. 
F463

Se repite el pictograma $\mathrm{F} 439$, que equivale a: hablar.

F464

También se repite F440; en ese lugar, junto con el pictograma anterior, maldecir y blasfemar. Aquí, de nuevo hay que dar prioridad al desarrollo del formulario, $\mathrm{y}$, en consecuencia, entenderlos como: pensar y desear.

F465

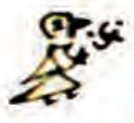

Pictograma que repite la figura de F049, que podría significar simplemente: hombre.

\section{F466}

Pictograma con la imagen de F067, repetida en F451. Con motivo del cuarto mandamiento (fundidos en un solo pictograma), he preferido el sentido: padre y madre. Pero aquí, (numerados como dos) con ocasión del noveno mandamiento, es preferible el de: hombre y mujer.

F467

La hilera de diez cuentas apunta al ordinal: el décimo.

F468-F469

Repiten los pictogramas F439 y F440. Como en el mandamiento anterior, al décimo mandamiento también corresponde el sentido de: pensar y desear.

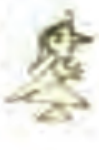

F470

Muy parecido a F101, hay, con todo, varias diferencias: La más notable es que el personaje que aparece aquí tiene la cabeza aureolada de rayos.; además, la cruz está tras el personaje, en lugar de aparecer a la derecha. Pero ambos están sentados a la mesa donde se ven las monedas. El sentido lo proporciona el formulario de los mandamientos: bienes de otro.

F471-F472

Aparece el guia, y el pictograma F005; ambos se entienden como: estos son.

\section{F 473}

Los diez círculos vuelven a constar, pero en una hilera vertical de ocho, y otra a la derecha con dos; es el numeral: diez.

\section{F474}

Este pictograma no aparece más que una vez. Dos círculos, 
dispuestos en vertical, están separados (¿o unidos?) por una línea horizontal, rematada a la derecha por una voluta que se cierra hacia abajo, y a la izquierda por otra que se cierra hacia arriba. Pese a ese adorno, parece que no hay que asignarle otro valor más que en numeral: dos.

F475

Repite el pictograma F033, con la equivalencia de: todo.

F476

Una figura estática, de frente, tiene en sus manos a ambos lados, dos cruces. No corresponde otro sentido más que: resumen.

F477

Lo mismo que en F473, una hila de ocho círculos y otra de dos representan los: diez.

F478

Un sólo círculo, denota el ordinal: el primero.

F479

Idéntico a F438, con el valor de: amar.

F480

Un círculo, pero que cambia el sentido de ordinal a adjetivo: único.

F481

Igual que F171, tiene el sentido de: Santo.

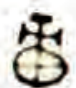

F482

Es, repetido, el pictograma F056, que corresponde a: Dios.

\section{F483}

El pictograma se compone de dos mitades, la de F033: todo, y la de F069: corazón. En conjunto es, pues: [de] todo corazón.

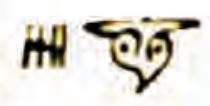

F484

Aparecen dos círculos en vertical (sin adornos como en F474); es el ordinal: el segundo.

\section{F485}

Repetición de F438, con la equivalencia de: amar.

F486

Dos figuras, prácticamente como en F450, tiene el valor de: prójimo.

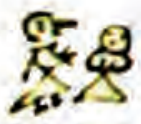


F487

Reproducción del pictograma F073: como, asi como.

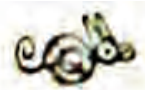

F488

Es calco de F486 (y de F450), pero el sentido del formulario, tomado de la afirmación evangélica, ha de llevar a entenderlo como: a ti mismo.

F489-F490

Repetición de los dos últimos (F487 y 488), como reiteración, subrayado, más que como plural.

A propósito de F094, está constatada otra repetición. Quizá se trate también ahora de un nuevo despiste del dibujante, en caso de estar copiando de otro ejemplar.

F491-494

Constituyen la repetición de la conclusión de los formularios: asi [se] haga, amén Jesús.

Estos son fpara los] ereen [enet]Señor Dios; [su] nombre, mandatos contra? [el] demonio (...) tierra. Estos son tiez; [su] nombre, mandamientos.

El primero amar fa] Dios [sobre\}todas flas] cosas.

Etsegundo [no] maldecir, blasfemar [sino] amar [su] nombre.

Etterecrosantifiear tomingo [en la] Iglesia; descanso hace [el] Hijo; rezo [al]

Santo.

El cuarto, ver [y] honrar [al] padre [y] madre.

El quinto, no matar.

El sexto, [no] fornicar,

El séptimo, [no] hurtar.

El octavo, [no] decir mentiras, [como el] demonio.

El noveno, [no] pensar [y] desear [al] hombre [y a la] mujer.

El décimo, [no] pensar [y] desear ]los] bienes de otro.

Estos son diez [que en] dos [del] todo [se] resumen los diez: el primero, amar [a un] único Señor Dios [de] todo corazón; el segundo, amar [al] prójimo como a ti mismo, a ti mismo.

4si [se] haga; amén Jesús.

\section{PARTE SÉPTIMA: FORMULARIO NO IDENTIFICADO (F495-F513)}

Al acabar los mandamientos entramos en el f. 13v, cuya primera banda está ocupada por los cuatro pictogramas de la conclusión. Pero de nuevo falta una o varias hojas, por lo cual, los pictogramas que siguen, los últimos conservados del catecismo, inician otro formulario que queda gravemente incompleto. 


\begin{tabular}{|l|l|}
\hline \multicolumn{1}{|c|}{ F. 13v } & Hoja que falta \\
\hline $\begin{array}{l}\text { F491: así/ F492: haga / F493: amén } \\
\text { / F494: Jesús }\end{array}$ & \\
\hline $\begin{array}{l}\text { F495: Señor / F496: Dios / F497: son } \\
\text { estos/ F498: ver }\end{array}$ & \\
\hline $\begin{array}{l}\text { F499: todo / F500: ? / F501: hablar / } \\
\text { F502: decir }\end{array}$ & \\
\hline $\begin{array}{l}\text { F503: pecado/ F504: Espiritu Santo } \\
\text { / F505: ángeles (?) }\end{array}$ & \\
\hline $\begin{array}{l}\text { F506: guí / F07: el primero / F508: } \\
\text { todo / F509: ? }\end{array}$ & t scguntto \\
\hline $\begin{array}{l}\text { F510: pensar de corazón/ F511: } \\
\text { tercero/ F512: guía/ F513: el cuarto }\end{array}$ & \\
\hline
\end{tabular}

A la vista de los pictogramas ordinales F507: el primero; F511: el tercero y F513: el cuarto, hay que pensar en un formulario que incluye cuatro o más miembros en su enumeración.

Si se pudiese interpretar el enunciado constituido por F511 y F512, daría la clave de qué formulario se trata, pero la interpretación de estos dos no puede ser más simple: el tercero, y la figura del guía que se entendería como: el, el que, y que deja todo en suspenso (aunque el personaje tenga dibujados en la parte posterior de la cabeza unos largos cabellos que sobresalen).

Cabría aún otra posibilidad: que a partir del pictograma que habría de seguir a F494 (Jesús) empezara un formulario breve; y que después de F505, terminara, para comenzar otro, que seguiría en el f.14v, o, si hubiera más hojas, en las siguientes.

Pero como se ve, todo son conjeturas. Los pictogramas que se han conservado, por sí mismos no arrojan luz suficiente para saber si se trata de un formulario o de dos; pero tampoco es posible sospechar de cuál se trata de los que habitualmente se encontraban en los catecismos.

Por consiguiente, salvo la primera banda de este f. 13v, que completa la serie de los mandamientos de Dios, el resto permanece mutilado, incompleto, y además resulta imposible sospechar de qué formulario se trata. Son ideas inconexas, carentes de sentido. Y la enumeración que se inicia hacia el final (primero..., tercero..., cuarto...) tampoco arroja tanta luz como para poder descubrirlo. 
Tanto este final mutilado, como la hoja primera en blanco, que apuntaba sin dificultad al credo, llevan a la conclusión patente de que el catecismo era más amplio. La carencia de hojas iniciales y finales, además de las intermedias señaladas dejan un agridulce sabor, por el hecho de que el conocimiento de lo que pudo tener este catecismo cuando se dibujó nos ha llegado de forma parcial. La ausencia del padrenuestro y del avemaría resultan evidentes en un texto que contiene lo fundamental de la fe cristiana.

Además de lamentar la pérdida, irreversible, hay que alegrarse por haber sido posible una lectura parcial, pero casi íntegra. Quedan —es cierto- algunas lagunas en la interpretación de lo conservado. Pero era necesario llevar a cabo el intento. Y ahí están los resultados, desvelando casi de forma completa lo que ha llegado a nosotros. En el resumen final no quedan reflejados los pocos pictogramas que, a continuación del credo, podrían pertenecer a la salve, pero que son pocos y carecen de fluidez en la interpretación. Tampoco figuran los del último formulario, incompleto e imposible de identificar. El resto, en el orden que llevan en el texto es: CREDO (Arreglar en montaje)

Groon Dios Padre este es [el que] hace tcito y la trerra. Groen Jesús humillado concebido [por su] madre por otra Estritu Santo, ella Maria sin

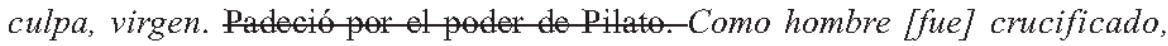
muerto $(. .$.$) seputato bajó al infierno; [al] tercer día resucitó glorioso de entre$ [los] muertos. Subió al cielo; está sentado a la derecha [del] Padre Dios todo hacedor. Desde alli bajará parajuzgar a todos [los] vivos y muertos. Creo en Dios Espiritu Santo, que hace [la] Iglesia católica, formada [por la] unión [de] todos los santos padres. Creo [que] formada [la] unión [de] todos [los] santos [en la] vida eterna.

\section{MANDAMIENTOS DE LA IGLESIA}

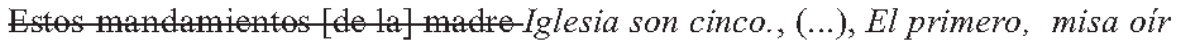
[los] domingos y fiestas. El segundo confesar el pecado tos los años por Pasecta una vez con dolor; su nombre, confesión. E1 terpo- [de] Jesucristo, [su] nombre, comunión. (Es su nombre comunión). El cuarto, ayunar [cuando] manda [la] madre Iglesia. El quinto, pagar [cada] diez; [su] nombre, diezmos. Son [los que] guardan, ven [los] santos vivos (...?) [que] hacen la unión, [su] nombre sagrado anuncio. Así [se] haga; amén Jesús.

\section{SACRAMENTOS}

Creo [que] estos son [los] divinos sacramentos [de la] madre Iglesia; son siete. El primero, echar agua, [su] nombre, bautismo. El segundo, ungir; [su] nombre, confirmación. El tercero, padecer, [su] nombre, penitencia. El cuarto, recibir [el] cuerpo [del] Señor Jesucristo; [su] nombre, comunión. El quinto, [al] enfermo 
angir [con] Santo (óleo?); [su] nombre, extremaunción. El sexto, [ser] sacerdote; 'su] nombre, orden sagrado es. El séptimo, hombre y mujer unidos; [su] nombre, natrimonio. Así se haga; amén Jesús.

\section{EXPLICACIÓN NO DENTIFICADA}

El muy Santo Dios, un Santo Dios que (...) ve; un santo Dios, el bendito Hijo el sielo ve y la tierra toda. El bendito Hijo que este es, ve [y] hace el cielo, ve la 'ierra. Ruego al único Santo Dios, el que es único Santo Dios, fue engendrado [de ina] madre, el que fue engendrado [de una] madre [por] el Dios Padre; Iesucristo, al que María... Maria sin culpa, virgen, prucificado, muerto [y] iepultado; tescentió al infierno [a] tereer día resucitó glorioso de entre tos mutros, subiư alcicto, está sentado a la derecha del Padre todo hactor. Deste thŕ bajará para juzgar tas yuertos. El que es (...) desde alli los vivos de corazón (...) el que cuerpo [de los] padres (...) cielo [la] vida eterna(?) es ianta (...). Rezo a los santos, rezo (...) demonio, demonio ... ... muertos bajan al infierno. [Los] muertos [que no] se ven santos padecen [con] el demonio. Estos hombres [que] mueren [por el] Santo Señor, Señor Dios, [con los] sacramentos. Lo dice [la] Iglesia: el cadáver [de] uno, la unión de todos los que confiesan ante Il Padre al Hijo [como] Señor, Señor (?) Jesucristo. Estos son santos como [los] zreen [los] hombres. Asi se haga, amén Jesús.

\section{ARTÍCULOS DE LA FE}

Creo [con los] hombres; creo, creo en verdad [al] Señor Dios, al único Santo, todo hacedor, [que] salva, salva al hombre, [y] santifica, al único [que] ama a [la] ierra. Creo [los] catorce; creo asi como la santa madre Iglesia. Estos son santos, 'que al] Santo creen; [por los] muertos rezo. Creo [sus] mandatos, mandamientos rdel] Santo; estos son [del] Santo Señor Dios. [Su] nombre: artículos [sobre] Dios o sobre la divinidad).

El primero, creo [en un] único Santo Dios todo hacedor.

El segundo, creo [en] Dios Padre.

El tercero, creo [en] Dios Hijo.

El cuarto, creo [en] Dios Espiritu Santo.

'El quinto], creo [en] un Santo Dios todo hacedor, [que] ve [el] pecado, todo recado, [que] ve todo, [que] ve [al] hombre.

El sexto, creo [en] Dios [que] salva, salva al hombre, [a] todo hombre.

El séptimo, creo [en] Dios [que] santifica.

Estos son [las] siete [que] creo afirmaciones, de [el] como hombre Señor tesucristo, hecho hombre.

El primero, creo [que el] Señor Jesucristo, [se] hizo ...hombre...) Dios Espiritu Santo.

El segundo ero [que el] Señor Jestreristo fue concebido madre mujer virgen [y] ració to una mujer.

El tercero creo [que el] Señor fesuristo [fue]eruiffato, voluntariamente muerto 
[para] satvar [a los] pecadores.

Eleurto creo [que el] Señor festreristo bajo a los inflemos [y] sepultado resucitó gtorioso.

$\ldots$

[lo que] manda el Señor Dios. Así se haga, amén Jesús.

MANDAMIENTOS DE Dios

Estos son [para los] eren [end] Señor Dios; [su] nombre, mandatos contra? [el] demonio (...) tierra. Estos son tive; [su] nombre, mandamientos.

El primero amar fa] Dios [sobre] tortas [las] cosas.

E1seguto [no] maldecir, blasfemar [sino] amar [su] nombre.

Etercesantificar tomingo [en la] Iglesia; descanso hace [el] Hijo; rezo [al]

Santo.

E1 cuarto, ver [y] honrar [al] padre [y] madre.

E1 quinto, no matar.

E1 sexto, [no] fornicar.

El séptimo, [no] hurtar.

El octavo, [no] decir mentiras, [como el] demonio.

El noveno, [no] pensar [y] desear [al] hombre [y a la] mujer.

E1 décimo, [no] pensar [y] desear ]los] bienes de otro.

Estos son diez [que en] dos [del] todo [se] resumen los diez: el primero, amar [a un] único Señor Dios [de] todo corazón; el segundo, amar [al] prójimo como a ti mismo, a ti mismo.

Así [se] haga; amén Jesús. 